\title{
LA REFORMA DEL SISTEMA ELECTORAL O LA CUADRATURA DEL CÍRCULO
}

ANTONIO TORRES DEL MORAL 
1.-INTRODUCCIÓN. 2.-CONCEPTOS GENERALES. 3.-PREGUNTA INICIAL E HIPÓTESIS DE TRABAJO: 3.1. ¿Qué se le pide al sistema electoral? 3.2. ¿Qué se le pide a la reforma del sistema electoral? 3.3. Cuatro hipótesis de trabajo. 4.-ORIGEN DEL SISTEMA ELECTORAL ESPAÑOL Y PRIMERA FORMACIÓN DEL SISTEMA DE PARTIDOS: 4.1. De la Ley para la Reforma Política al artículo 68 de la Constitución. 4.2. Formación del sistema de partidos. 5.-EVOLUCIÓN POSTERIOR: 5.1. ¿Sistema o subsistemas electorales? 5.2. ¿Sistema o subsistemas de partidos? 5.3. El inencontrable pluripartidismo del sistema político nacional. 6.-INTERMEDIO: SISTEMA ELECTORAL Y DE PARTIDOS DE LAS COMUNIDADES AUTÓNOMAS: 6.1. Rasgos principales. 6.2. El casi inencontrable pluripartidismo autonómico. 7.-HOMOGENEIZACIÓN DEL COMPORTAMIENTO DEL ELECTORADO EN LAS ELECCIONES GENERALES Y AUTONÓMICAS. 8.-ABANDONO DE LA OPCIÓN INICIAL DEL SISTEMA: EL MAL BIPARTIDISMO Y EL BUEN PLURIPARTIDISMO. 9.-LOS PARTIDOS NACIONALISTAS: 9.1. La no sobrerrepresentación de los partidos nacionalistas. 9.2. La posición intocable de los partidos nacionalistas en el sistema electoral. 10.-MAYORÍA DE VOTOS, MAYORÍA DE ESCAÑOS Y FORMACIÓN DE GOBIERNO, TRES EFECTOS ELECTORALES NO SIEMPRE SECUENCIALES. 11.-CONCLUSIONES DEL ANTERIOR ANÁLISIS. 12.-PROPUESTAS DE REFORMA: 12.1 La supuesta rigidez fáctica de las leyes electorales. 12.2 Reforma electoral sin reforma constitucional: 12.2.1. Sobre la constitucionalidad de las bolsas nacionales de escaños. 12.2.2. Cambiar de fórmula de distribución de los escaños. 1.2.3. Rebajar la cuota fija provincial. 12.2.4. Aumentar el número de escaños a 400. 12.2.5. Modificación combinada de dos o más elementos del sistema. 12.3. Reforma electoral con reforma constitucional. 13.-LA REPRESENTACIÓN COMO REFLEJO Y COMO INTEGRACIÓN EN EL SISTEMA. 14.-PROPUESTA FINAL. 15.-UN EPÍLOGO DESDE LA PERPLEJIDAD. 


\title{
LA REFORMA DEL SISTEMA ELECTORAL O LA CUADRATURA DEL CÍRCULO
}

\author{
POR \\ ANTONIO TORRES DEL MORAL \\ Catedrático de Derecho Constitucional \\ UNED
}

\section{INTRODUCCIÓN}

Hace unos días Daniel INNERARITY escribía en un lúcido artículo de prensa que ha terminado la era de la certeza y ha comenzado la de la incertidumbre. Hay que vérselas con la incertidumbre, con la inestabilidad y con el riesgo. No es verdad que para cada problema estemos siempre en condiciones de generar el saber correspondiente para solucionarlo.

Cierto. Pero no podemos dejar de arriesgarnos; sólo que debemos andar con tino para saber administrar el riesgo.

Desde la otra acera epistemológica, se suele decir que un problema bien planteado es un problema semirresuelto. No estoy seguro. El hombre tiene una capacidad inquisitiva mucho mayor que de respuesta, lo mismo que sus dotes destructivas superan con creces a las creativas. Pero conviene no pasarse, no vaya a ocurrirnos como a aquel filósofo que era tan escéptico que no creía ni en el escepticismo, con lo que automáticamente caía de bruces en el dominio del nihilismo o, valga la paradoja, en el dogmatismo.

Nunca se dejará de escribir sobre la democracia, decía G. BURDEAU, el fino constitucionalista francés, pronóstico que casi me atrevería a calificar de bas-

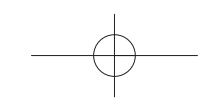


tante obvio. Democracia ha llegado a ser en nuestra cultura jurídica y política euroatlántica, sinónimo de legitimidad y ésta es el norte de toda Teoría Política que se precie. De igual modo, nunca se dejará de escribir sobre las elecciones, porque la democracia ha devenido — no sólo, pero sí fundamentalmentedemocracia representativa y, por ende, electoral, dado que las elecciones son el presupuesto inexcusable de la representación política.

Pero no es inoportuno que desde estas mismas palabras introductorias dejemos patente nuestra posición respecto de una cuestión que, de un lado, es preliminar al objeto del Seminario, y, de otro, estará presente explícita o implícitamente en todo su desarrollo: desde el punto de vista de la Teoría democrática, ni por un momento puede dudarse del carácter representativo de nuestro Congreso de los Diputados. Pese a la mucha letra impresa que se desperdicia en sentido contrario, es de resaltar que la composición de nuestra Cámara Baja es más, mucho más representativa (en el sentido tradicional del concepto de representación, esto es en la traducción de votos en escaños) que la Cámara de los Comunes británica y que la Asamblea Nacional francesa. El problema se plantea con mayor sentido si damos entrada al concepto subjetivo de representación. Lo haremos en el epígrafe 13 de este trabajo.

Nos las habemos, pues, con el sistema electoral y con su eventual reforma. Como ha escrito L. LÓPEZ NIETO, las reglas de juego de un sistema político están conformadas en buena parte por los sistemas electorales, que incluyen un conjunto de elementos básicos, cuales son la circunscripción electoral, la fórmula de escrutinio y las garantías democráticas que salpican cada fase del proceso electoral. Además, cada sistema electoral se elabora para cumplir objetivos concretos y las modificaciones que sufren son escasas, porque requieren apoyos sólidos para garantizar los objetivos que se pretenden alcanzar ${ }^{1}$.

Se entiende, por tanto, que en este Seminario trataremos con dicho objeto y que ya contamos, de antemano, con su mentada dificultad. Huelga decir que, con toda seguridad, no podremos solucionar los problemas del sistema electoral español, pero debemos esforzarnos para que, al menos, queden planteados con la mayor nitidez posible. Es importante ceñirse a este más modesto propósito porque, volviendo al teorema anterior, cabe reformularlo de manera negativa y mucho más certera: un problema mal plantado resulta irresoluble. Ése es el compromiso que contrae esta ponencia: evitar, en lo posible, los planteamientos erróneos, al menos los más groseramente erróneos.

1 LÓpez Nieto, L.: «Análisis de las elecciones autonómicas», 2006-2007, documento elaborado para apoyo a la docencia, disponible en la web de la UNED. http://uned.es/dcpa/Asignaturas/Analisis_elecciones_autonomicas_.doc 


\section{CONCEPTOS GENERALES}

He definido en otra obra el sistema electoral como «el conjunto de reglas y procedimientos conforme a los cuales se convocan y celebran las elecciones, se asignan los escaños a tenor de los votos obtenidos por las candidaturas y se resuelven los recursos a que todo este proceso diere lugar» ${ }^{2}$.

D. W. RAE considera que el sistema electoral es «el conjunto de normas procedimientos y técnicas que rigen el proceso electoral por el que las preferencias de los ciudadanos se articulan en votos y estos votos son traducidos en una distribución de autoridad gubernamental, normalmente escaños parlamentarios, entre los distintos partidos políticos contendientes» ${ }^{3}$. Es éste un concepto poco técnico, poco preciso, pero que, no obstante, destaca algo especialmente pertinente para el presente trabajo: de todos los elementos del sistema electoral, nos interesan aquellos que determinan esa traducción de votos en escaños; son los elementos de mayor significado político y, por tanto, pueden ser entendidos como los centrales del sistema electoral.

Como dice el citado autor, las soluciones a las diversas cuestiones electorales son interdependientes; por eso, debemos añadir, constituyen un sistema, porque «la solución a cualquiera de ellas limita las soluciones que razonablemente puede ofrecer la ley a las demás... Es esta interdependencia la que conduce a politólogos y políticos por igual a considerar como un todo orgánico el modelo general de ley electoral que prevalece en las elecciones de un país»" ${ }^{4}$.

De otro lado, el sistema electoral influye en el de partidos y finalmente en el sistema político en varios aspectos, como es unánimemente asumido en la literatura sobre la materia, dado que limita el número de partidos que acceden al Parlamento, reduce aún más el de los que pueden constituir grupo parlamentario y suele dejar en uno o en muy pocos los que tienen opción de formar Gobierno. Es decir, el sistema electoral — todo sistema electoral- simplifica la complejidad de la política resolviendo el multipartidismo que arroja el Registro de Partidos en un número manejable de propuestas políticas que se hacen pre-

2 Torres del Moral, A.: Estado de Derecho y democracia de partidos, Servicio de Publica-

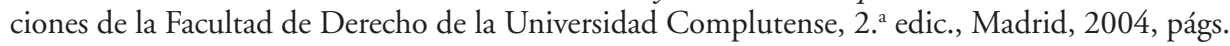
373-374.

3 RAE, D. W.: Leyes electorales y sistemas de partidos políticos, CITEP, Madrid, 1977, pág. 14. En un sentido similar, P. Santolaya define el sistema electoral por aquellos elementos que tienen una incidencia directa en la mediación entre votos y escaños, de manera que a igual número de sufragios pueden producir una distinta composición partidista del ente representativo (Manual de procedimiento electoral, Ministerio del Interior, Madrid, 1991, pág. 11).

${ }^{4}$ RAE, D. W.: Leyes electorales..., ob. cit., págs. 14-15. 
sentes en el Parlamento. Desde este punto de vista, el sistema electoral es un cementerio de partidos. Es de señalar que en nuestro país son más los partidos que desaparecen por sus malos resultados electorales que los que aparecen buscando fortuna en unos comicios. A su vez, de estos últimos, pocos son los que sobreviven a un par de elecciones 5 .

Esta selección la hacen los sistemas de fórmula proporcional, ora ajustándose a la más estricta justicia electoral, ora «interpretando» los resultados mediante una fórmula de asignación de los escaños que es, en principio, igual para todos, pero que, por la incidencia de otros elementos del sistema, resulta favorable a algunos contendientes.

En cuanto al sistema de mayorías, la selección se realiza de manera brutal (como brutal ha sido calificado el sistema electoral británico) por la pérdida de la mitad de los votos emitidos por los electores, o incluso más, si el país no es estrictamente bipartidista, como sucede en el Reino Unido.

En segundo término y como consecuencia de lo anterior, el sistema ${ }^{6}$ electoral influye en el perfil que termina adoptando el sistema político, puesto que facilita o dificulta la formación de los Gobiernos y su estabilidad. Bien es verdad que, como dicen I. DELGADO SOTILLOS y L. LÓPEZ NIETO, la estabilidad requiere el funcionamiento satisfactorio de muchos componentes diferentes; por eso, incluso el mejor sistema electoral no puede compensar todas las posibles disfunciones del sistema político, como las de la estructura política o la de la cultura cívica ${ }^{7}$.

Por la índole del presente trabajo, voy a operar con un concepto restringido de sistema electoral, fijándome preferentemente en algunos elementos claves del mismo que puedan incidir más en la configuración de un sistema de partidos y en la formación del Gobierno, aunque desde un saludable escepticismo respecto de las «leyes» de DUVERGER en la materia. De entre todos ellos, destacaremos:

- la circunscripción

- la fórmula de asignación de los escaños

5 El Centro Democrático y Social, liderado por Adolfo Suárez, sobrevivió a tres; tras la retirada de su líder, se deslizó por una penosa pendiente totalmente desnaturalizado.

${ }^{6} \mathrm{Al}$ ponerlo en relación con el sistema político, sería más adecuado decir subsistema electoral, ya que es una pieza de aquél. Lo mismo podríamos decir del sistema de partidos. La comodidad nos lleva, en cambio, a prescindir de la precisión.

7 Delgado Sotillos, I., y López Nieto, L.: Comportamiento político y Sociología electoral. Unidad Didáctica, UNED, Madrid, 2008, pág. 81. 
Así mismo debemos tener en cuenta otros factores o variables igualmente influyentes en el funcionamiento del sistema. Entre otros:

- el comportamiento electoral

- el distinto ámbito territorial de las convocatorias (nacional, autonómico, municipal o europeo)

- el fenómeno del regionalismo y de su versión más radical: el nacionalismo.

En cambio prescindo de otros elementos como las listas cerradas y bloqueadas, o lo contrario, porque inciden menos en el sistema de partidos, aunque sean muy interesantes desde otro punto de vista de la representación política al que aludiremos más adelante.

\section{PREGUNTA INICIAL E HIPÓTESIS DE TRABAJO}

\section{1. ¿Qué se le pide al sistema electoral?}

Las elecciones no son un fin en sí mismas, sino un medio de provisión personal de determinados órganos políticos, primordialmente del Parlamento. El fin está en esa correcta composición, pero el medio utilizado para ello, las elecciones, condiciona el ulterior funcionamiento del Parlamento y, a su través, de todo el sistema político. Puede decirse, por tanto, que no hay un buen sistema político con un mal sistema electoral. Lo difícil es saber qué es un buen sistema electoral, cuestión a la que nunca se llegará a dar una respuesta que satisfaga a todos. Por eso nunca se dejará de hablar ni de escribir sobre elecciones. Pero, cuidado, si las comedias de Lope de Vega pasaban en horas veinticuatro de las musas al teatro, en política y en Derecho hemos de huir de las genialidades y de los milagros.

A la hora de adoptar un sistema electoral, lo primero que hay que saber es lo que se pretende de él. Frente a concepciones simplistas que lo reducen todo al sufragio universal, es bien cierto que, con unos resultados electorales determinados medidos en número de votos, diferentes sistemas electorales producen resultados "políticos» distintos, medidos en términos parlamentarios, que son los finalmente determinantes para la gobernación del país.

Pues bien, la primera respuesta, la más elemental y fundamental, a la pregunta de qué se pide al sistema electoral es la de que proporcione legitimidad al sistema político. Pero esta respuesta nos va a ser poco útil por cuanto ese resul- 
tado lo consideramos inherente a todo proceso electoral que se acometa en un clima de normal ejercicio de libertades públicas y derechos políticos. No hay en ello superioridad de un sistema sobre otro, siempre que ambos sean democráticos: ni del sistema proporcional sobre el de mayorías, ni viceversa. No es más democráticamente legítimo el sistema político español que el británico, ni al contrario, en función sólo de sus diferentes sistemas electorales.

La idoneidad de uno u otro sistema electoral es un problema recurrente en la Teoría Política. En favor de las fórmulas de mayoría se suelen emplear argumentos de eficacia, porque posibilitan la formación de Gobiernos homogéneos y estables, y de vinculación estrecha entre el diputado y sus electores. A favor de las fórmulas proporcionales, argumentos de justicia electoral y de eliminación de votos sobrantes porque todos tienen su traducción alícuota en escaños.

Sin embargo, la investigación comparatista no nos depara resultados consolidados. No es cierto que con sistemas de mayoría se consigan siempre y de forma automática gobiernos estables, como tampoco lo es que las fórmulas de proporción provoquen inestabilidad gubernamental. La sola evocación de la alta estabilidad gubernamental alemana, e incluso española actual, con sistemas proporcionales, frente a la inestabilidad de nuestra Segunda República, con sistema de mayoría, nos libera de la necesidad de presentar argumentaciones más teóricas.

Ahora bien, dentro de cada sistema electoral sí se pueden disponer sus elementos de manera que, en algún caso, se resienta su legitimidad, como, por ejemplo, dentro del proporcional, disponer una barrera electoral del 20 o del 30 por ciento. No hay que aclarar que esta barrera existe en España, concretamente en el sistema electoral canario, y que el Tribunal Constitucional la ha declarado conforme a la Constitución en dos de las peores sentencias que le recuerdo $^{8}$, y recuerdo muchas. Pero no hay elementos de este tipo en el sistema que rige para las elecciones generales, por lo que prescindiremos de la anécdota.

Centrándonos, pues, en aquella pregunta inicial, las posibles respuestas a la misma son, en síntesis, tres:

a) que la conformación de la Cámara represente a escala la opinión de los electores o voluntad general, por decirlo en términos clásicos, hoy acaso desusados;

b) que facilite la formación de los Gobiernos y disminuya los riesgos de crisis y de vacíos de poder, aunque sea forzando un tanto los números;

c) ambos resultados a la vez.

8 En la STC 72/1989, de 20 de abril, homologó la barrera del 20\% ¡como garantía del pluralismo!, y en la 225/1998, de 25 de noviembre, la del 30\%. 
Lógicamente, la primera tarea consiste en lograr un acuerdo sobre la respuesta a esa pregunta inicial, y la segunda, sobre cómo llevarla a la práctica, esto es, sobre qué elementos del sistema debemos operar para conseguir nuestro propósito.

\section{2. ¿Qué se le pide a la reforma del sistema electoral?}

De lo expuesto en el anterior epígrafe cabe deducir que la reforma del sistema electoral depende igualmente de lo que se pretenda de la misma, pero ya con uno o varios pies forzados por cuanto ya existe un sistema en vigor. Es decir, debemos saber qué elementos del sistema vigente se quiere modificar con vistas alcanzar un determinado objetivo: si la fórmula de escrutinio, si la papeleta electoral, si la circunscripción electoral, si la asignación de escaños a cada circunscripción, etc.; pero, a la vista de que unos de esos elementos están constitucionalizados y otros no, hay que despejar la incógnita de si se quiere una modificación del sistema electoral con reforma constitucional o meramente con reforma de la legislación infraconstitucional.

Ahora bien, en España nadie o casi nadie propugna de momento el paso del sistema proporcional existente para el Congreso de los Diputados a un sistema de mayorías, sino, en todo caso y solamente por parte de algunos, una profundización en el vigente para alcanzar una mayor proporcionalidad. Los medios de comunicación vienen recogiendo en los últimos años, y más aún tras las elecciones generales de marzo de 2008, diversas posiciones en torno a dicha reforma dirigidas a tal fin y/o para menguar en lo posible el bipartidismo. Ésta es la idea de Izquierda Unida, que ve cómo una y otra vez supera en votos a los partidos nacionalistas y es superada por éstos en escaños.

Desde luego, ambos propósitos son políticamente defendibles. De lo que se trata en un estudio como éste es de ver si resulta factible su consecución y, en todo caso, si nuestro sistema electoral debe ser modificado para este $\mathrm{u}$ otro propósito y cuáles son los condicionamientos técnico-jurídicos de tal empresa.

Para ello, habremos de ir despejando las posibilidades que nos ofrece la alteración de los elementos del sistema uno por uno. Ello nos permitirá obtener unas respuestas rectilíneas y comprensibles, pero sólo nos ofrecerá fotografías instantáneas de las diferentes vertientes del problema, aparentemente muy nítidas, pero demasiado elementales. Para obtener respuestas más complejas y comprehensivas de la realidad, habremos de pensar en la combinación de más elementos en el análisis a fin de no distorsionar la visión del problema. 
De una parte, si los fines postulados son, a un tiempo, mejorar la proporcionalidad del sistema electoral e incrementar la gobernabilidad, hemos de convenir en que estamos pidiendo al sistema electoral resultados que acaso no sean siempre convergentes, o no lo sean del todo, lo que puede dificultar la respuesta o hacerla más compleja que si respondemos por separado a dichas demandas. Me temo, sin embargo, que, a los efectos de la presente ponencia, habremos de incurrir en una cierta elementalidad en la exposición, en aras de la brevedad y para dar más tiempo al debate.

De otra, hemos de convenir también en que, si se va buscando una reforma del sistema electoral que no requiera reforma constitucional, por las obvias razones de su dificultad, no tanto jurídica, no deben abrigarse demasiadas esperanzas de que la mejora sea sustancial, puesto que, como hemos adelantado, los elementos esenciales del sistema están precisamente en la Constitución.

Por último, en función de todo lo anterior, no hace falta hacer advertencia alguna acerca de que el análisis que sigue a este breve exordio, y muy principalmente la formulación de las consecuencias que pueda tener la modificación de este o aquel elemento del sistema electoral, están hechos, como es de rigor, dando por aceptadas las cláusulas rebus sic stantibus y coeteris paribus.

\subsection{Cuatro hipótesis de trabajo}

De este modo, se trata de realizar un análisis en el que, partiendo de una base jurídico-positiva determinada - Constitución española, Ley Orgánica del Régimen Electoral General (en adelante, LOREG), Estatutos de Autonomía y leyes electorales autonómicas-, se incorporen variables externas (comportamiento electoral, contexto político, etc.), que nos permitan verificar o falsear una primera hipótesis de trabajo, que paso a formular:

la tendencia cada vez mayor hacia unos resultados electorales muy competitivos entre las dos formaciones políticas mayoritarias en todo el territorio nacional (PP y PSOE).

Dicho de otro modo,

la progresiva tendencia hacia un cuasibipartidismo, que no llega a ser un bipartidismo canónico debido principal pero no únicamente a la existencia de fuertes formaciones nacionalistas en determinadas Comunidades Autónomas.

El resultado que obtengamos en esta primera parte del trabajo puede colorear la formulación de la segunda hipótesis y de su correspondiente análisis, pero 
no la impide por cuanto la cuestión de si es posible, o necesaria, o conveniente, y cómo, la reforma de la legislación electoral está siempre abierta. Las hipótesis de trabajo en esta segunda parte son varias, según se pretenda hacer las modificaciones correspondientes con o sin reforma de la Constitución:

1. a) Una alteración del sistema electoral que alcance sin límite al artículo 68 constitucional es, además de jurídicamente muy costoso, políticamente impensable.

2. $\left.{ }^{a}\right)$ Si no se revisa el carácter proporcional del sistema, las demás modificaciones, fundamentalmente las que afecten a las circunscripciones electorales, tendrán mayor o menor alcance en función, de nuevo, de si se retoca la Constitución o no.

3. $\left.{ }^{a}\right)$ Ciñéndonos a las pretensiones más modestas, es factible una reforma del sistema electoral que mejore su proporcionalidad y dé satisfacción parcial a las formaciones políticas actualmente perjudicadas por la rigidez de dicho sistema.

\section{ORIGEN DEL SISTEMA ELECTORAL ESPAÑOL Y PRIMERA FORMACIÓN DEL SISTEMA DE PARTIDOS}

\subsection{De la Ley para la Reforma Política al artículo 68 de la Constitución}

Decía ORTEGA que el hombre no tiene naturaleza sino historia. No parece inoportuno, por ende, que hagamos un poco de memoria para ilustrar, bien que muy sintéticamente, cómo se fraguó el sistema electoral general. El hecho de que continúe vigente nos persuade de que en su origen deben estar sus claves y su esqueleto. Y es que, si queremos introducir modificaciones legislativas, conviene que conozcamos la realidad que vamos a someter a norma porque, si bien en ocasiones esa realidad termina adaptándose al corsé que se le impone, en otras se resiste hasta hacerlo estallar.

Pues bien, a fines de 1976, cuando el Gobierno de Adolfo Suárez presentó a las Cortes franquistas el proyecto de Ley para la Reforma Política, los teóricos y los políticos españoles (con algunas excepciones entre los primeros) suscribían las «leyes» de DUVERGER sobre las relaciones entre los sistemas electorales y los de partidos. Son tesis muy primarias y susceptibles de matices y excepciones, que ya algunos politólogos, como SARTORI y LAVAU, habían puesto de relieve, pero que en el fondo acertaban a identificar lo más elemental de esas relaciones. El redactor del mentado proyecto las tuvo en cuenta, aunque las rodeó de dichos matices.

Como he escrito en otro lugar, las tales Cortes estaban conmovidas: en el proyecto se hablaba de voluntad popular, se diseñaban unas Cortes bicamerales 
elegidas por sufragio universal y se establecía el escrutinio proporcional para la Cámara Baja. Demasiado para digerirlo de una sola vez?

De manera que, en primer lugar, quien ideó nuestro sistema electoral, en atención al contexto político y social español de aquel momento, tras la desaparición física del dictador, prefirió el sistema proporcional para el Congreso de los Diputados buscando:

Evitar la división, una vez más, de «las dos Españas» ${ }^{10}$; en cambio, los procuradores franquistas preferían el sistema de mayoría porque entendían que con él tendrían más posibilidades los notables de cada localidad, entre los que creían encontrarse.

Evitar una de las consecuencias que entonces se esgrimían contra el sistema proporcional, a saber, la producción de un pluralismo atomizado de partidos y la dificultad para formar Gobierno; para ello introdujo ciertas variables y condiciones que pretendidamente evitarían el mentado fraccionamiento de la Cámara.

Por el contrario y al mismo tiempo, evitar también la reducción al silencio de voces que expresaran la pluralidad territorial española, esto es, la de los partidos políticos nacionalistas. Éstos esgrimían como bagaje democrático su presencia en la II República y su antifranquismo durante la Dictadura, y lograron que la opinión dominante en la clase política española de la transición aceptara que la legitimidad democrática del sistema político que estaba construyéndose pasaba ineludiblemente por la presencia en él de dichas fuerzas políticas. Había,

${ }^{9}$ Es de grata memoria la celebración en el Hotel Eurobuilding, de Madrid, de un Congreso organizado por el Centro de Investigación de Técnicas Electorales y Políticas (CITEP), sobre Leyes electorales y consecuencias políticas (editado después por dicha entidad con este mismo título, Madrid, 1977), en el que participaron politólogos y constitucionalistas españoles y extranjeros (con la tímida asistencia de quien escribe estas páginas como socio fundador del ente organizador), al mismo tiempo que se celebraban en las Cortes franquistas las sesiones para la aprobación de la Ley para la Reforma Política. En el Congreso de CITEP se defendió el sistema proporcional; en las Cortes se quería un sistema de mayorías. Algún procurador hizo declaraciones quejosas de tal coincidencia temporal y aseguró que las Cortes no necesitaban profesores extranjeros que les dijeran qué sistema electoral debían adoptar. Cuando llegó al Congreso (científico) la noticia de que las Cortes habían aprobado la mencionada ley con el sistema proporcional propuesto, prorrumpió en un cerrado aplauso.

${ }^{10}$ Es también de recordar, a este respecto cómo un renombrado sociólogo hispano-norteamericano, J. Linz, había pronosticado que las primeras elecciones libres en España darían como resultado la hegemonía del Partido Comunista y de la Democracia Cristiana. El Partido Comunista obtuvo 20 escaños y la Democracia Cristiana, ninguno. El pronóstico erró de medio a medio. Pero seguramente, el legislador quiso contribuir al fracaso de dicho mismo disponiendo un sistema proporcional. 
pues, un deseo muy explícito de integrarlas en el sistema naciente, o, por mejor decir, de facilitarles esa integración.

El Gobierno y el Presidente de las Cortes lograron sacar adelante la mentada ley incluyendo una disposición transitoria que decía:

«Se aplicarán dispositivos correctores para evitar fragmentaciones inconvenientes de la Cámara, a cuyo efecto se fijarán porcentajes mínimos de sufragios para acceder al Congreso».

En una palabra, se preveía la inclusión en la normativa pertinente de una barrera electoral. Tal normativa se publicó con fecha de 18 de marzo de 1977 bajo la forma de Decreto-ley y fijó dicha barrera en el 3\% de los sufragios de cada circunscripción. Igualmente, se adoptó la variante de D'Hondt de entre las posibles dentro de las fórmulas proporcionales en la creencia explícita de que también ésta contribuiría al mismo fin, pues decía, en efecto, que:

«[la regla de D’Hondt] supone un poderoso corrector del excesivo fraccionamiento de las representaciones parlamentarias».

Estaba el redactor del decreto-ley en un doble error porque la variante de D'Hondt no produce tal efecto por sí misma. Lo advirtió con énfasis D. NOHLEN:

«Nada más falso que eso. El método de D’Hondt casi no influye en nada en el fraccionamiento ni positiva ni negativamente. No se sabe en qué experiencia o literatura se basa dicho argumento», siempre, claro está, «que los otros factores... no impidan tal proporcionalidad, como es el caso del distrito de tamaño pequeño» ${ }^{11}$.

Como tampoco la barrera electoral del 3\% llegaría a servir de nada, o de casi nada, a la hora de evitar la fragmentación parlamentaria dadas las exiguas dimensiones de las circunscripciones españolas ${ }^{12}$.

La clave reside en otro sitio. La Ley para la Reforma Política estableció otros tres elementos del sistema electoral que sí han influido en la concentración de partidos presentes en el Congreso. A saber:

- La circunscripción provincial.

- La asignación a cada provincia de un mínimo inicial de escaños además de los que les corresponden por su población.

- El número total de 350 diputados.

${ }^{11}$ NoHLEn, D.: Análisis del sistema electoral español, CITEP, Madrid, 1977, pág. 3.

${ }^{12}$ Ha tenido aplicación en dos ocasiones, en la circunscripción de Madrid.

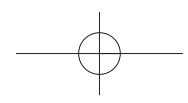


Con estos mimbres tenía que hacer el cesto electoral el citado decreto-ley, que, por si acaso, acentuó el envite. Veámoslo.

La fórmula de D'Hondt sí produce el efecto mencionado en circunscripciones pequeñas, como son las españolas en su mayoría. A este respecto, se suelen distinguir tres niveles o dimensiones en las circunscripciones: se estima que son pequeñas las que tienen de dos a cinco escaños ${ }^{13}$; medianas, aquellas en las que se ventilan de seis a diez, y grandes, las que ponen en liza más de diez ${ }^{14}$. A decir verdad, todas las fórmulas del sistema proporcional arrojan tal consecuencia de evitar la fragmentación de la Cámara si operan sobre circunscripciones pequeñas por la sencilla razón de que, si hay pocos escaños a repartir, sólo algunas candidaturas entrarán en el reparto; de esta manera los partidos con verdadero protagonismo político se reducen a muy pocos. La fórmula de D'Hondt acentúa dicho efecto más que algunas (por ejemplo, la de resto mayor y la de Santa Lagüe corregida) y menos que otras, como la de Santa Lagüe en su versión inicial y más conocida.

(En un epígrafe posterior volveremos sobre estas fórmulas y sobre su eventual utilización en una operación de reforma.)

El decreto-ley electoral de 18 de marzo de 1977 tuvo a bien fijar en dos escaños el mínimo provincial, adjudicar sendos escaños a Ceuta y Melilla y distribuir los 248 restantes con criterio poblacional. Justificó este documento la medida como una forma de suavizar los efectos de nuestra irregular demografía y de atender a un mayor equilibrio territorial en la representación ${ }^{15}$. Explicación

13 Es usual en la literatura científica sobre la materia, cifrar los escaños de la circunscripción pequeña en de tres a cinco, considerando que, con menos de 3, la elección se resuelve por mayoría de votos. No es cierto. Con dos escaños cabe la proporcionalidad, incluso, en ocasiones, más que con tres. Con dos escaños y fórmula D'Hondt, una candidatura sólo puede ganar los dos escaños si obtiene más del doble de votos que la segunda o el doble justo, mientras que el sistema de mayorías le atribuye los dos escaños incluso con un solo voto de diferencia. El ejemplo de Soria en las últimas elecciones generales es concluyente: con dos escaños, uno ha sido para PP y otro para PSOE, en tanto que en las nueve elecciones anteriores, al repartirse tres escaños, el PP (o UCD en su momento) doblaba los escaños del PSOE cuando sus cifras de votos distaban mucho de esa proporción. Ha sido, pues, más ajustada la distribución actual que la pretérita y así es probable que siga siendo en el futuro rebus sic stantibus.

${ }^{14}$ Como es lógico, se pueden adoptar cuadros más complejos, y cuantos más niveles distingamos, mayor será la precisión de nuestro análisis. Así, por ejemplo, FERNÁNDEZ SEGADO, F. (Estudios de Derecho Electoral, Ediciones Jurídicas, Lima, 1997, págs. 57-59) prefiere señalar cuatro, distinguiendo una magnitud media baja y otra media alta y reservando la calificación de alta o grande a la circunscripción con más de veinte escaños. Pero, para ilustrar el caso español, basta con las dimensiones apuntadas, que son las que se suelen utilizar más frecuentemente.

15 Decreto-ley sobre normas electorales, Exposición de Motivos [sic] (más correcto sería decir Preámbulo), apartado IV. 
que mereció cierta polémica, de la que me he ocupado en otro lugar, al que remito $^{16}$.

Como consecuencia, el mapa electoral español de 1977 ofreció el siguiente perfil:

- 7 provincias con tres escaños ${ }^{17}$;

- 8 con cuatro escaños.

- 13 con cinco escaños.

- 18 eran medianas (de seis a diez escaños);

- y 4 (Madrid, Barcelona, Valencia y Sevilla) como únicas circunscripciones grandes ${ }^{18}$.

Dicho de otro modo, de 50 circunscripciones (dejando aparte Ceuta y Melilla, que, con un solo escaño, tienen un sistema de mayoría y no se prestan a este análisis), 28 eran pequeñas (algunas, muy pequeñas), en las que la proporcionalidad resulta ser escasa, y muy alta, en cambio, la tendencia bipartidista. Y 18 eran medianas, en las que únicamente tres o cuatro candidaturas tienen posibilidades de alcanzar un escaño; en ellas, coeteris paribus, la tendencia al bipartidismo es algo menor que en las anteriores, pero sigue siendo acentuada. (La cautela que acabo de introducir tiene que ver, claro está, con la entrada en escena de los partidos nacionalistas en sus respectivas circunscripcio-

16 Torres del Moral, A.: "Composición del Congreso de los Diputados», Revista de la Facultad e Derecho de la Universidad Complutense (RFDUC), n. ${ }^{\circ}$ 58, Madrid, 1980. A favor se manifestó O. AlZAGA, que, sin embargo, reconocía que con ello se daba una prima electoral a la España más conservadora (Constitución española de 1978. Comentario sistemático, Ed. del Foro, Madrid, 1978, págs. 461-462. En contra, NoHLEN, D.: Análisis del sistema electoral español, ob. cit., pág. 4, y MarTínez SOSPEDRA, M.: «Desigualdad y representación en la Constitución española de 1978: el caso de las Cortes Generales", en Aparicio, M. A. (coord.): Parlamento y sociedad civil (Simposium), Universidad de Barcelona, 1980, págs. 196-211. En tono menos crítico se manifiesta L. López GUERRA: Introducción al Derecho Constitucional, Tirant lo Blanch, Valencia, 1994, págs. 146-147), «siempre que la ventaja no sea evidentemente desproporcionada».

${ }_{17}$ De ellas, una, Soria, ha pasado a tener sólo dos en 2008; y de tres escaños hay ocho.

18 Esta distribución ha ido reajustándose conforme a los movimientos demográficos. Unas provincias han perdido escaños y otras lo han ganado. El mapa, no obstante, sigue siendo semejante. Para las elecciones generales de 2008, la distribución de escaños ha sido la siguiente:

- 25 circunscripciones pequeñas: 1 (Soria), con dos escaños; 7 con tres, 9 con cuatro y 7 con cinco;

- 20 circunscripciones medianas: 8 con seis, 4 con siete, 5 con ocho, 1 con nueve y 2 con diez;

- 5 circunscripciones grandes: 2 don doce; 1 con dieciséis, 1 con treinta y uno, y 1 con treinta y cinco. 
nes.) En fin, las 28 circunscripciones pequeñas y cuatro de las medianas estaban sobrerrepresentadas.

En las condiciones descritas era y es muy difícil que un sistema proporcional arroje resultados que hagan honor a su nombre.

Por lo demás, no creo aventurado presumir que el autor o autores del diseño acariciaran la idea de que podrían conseguirse con él cuatro objetivos, algunos de los cuales ya han sido apuntados:

1. $\left.{ }^{\circ}\right)$ Con la opción por el sistema proporcional, como hemos indicado, evitar la excesiva polarización de la política española en dos bloques irreconciliables, con cambios bruscos en la composición de los Gobiernos a cada variación del electorado y con la propensión a la estrategia de frentes, de tan mal recuerdo entre nosotros; era una apuesta por un pluralismo atenuado en el que se cimentara una cultura de la negociación y del pacto de Estado.

2..$^{\circ}$ Como consecuencia de lo anterior, la probable formación de Gobiernos de coalición.

3..$^{\circ}$ Con la inclusión de correctivos a la proporcionalidad se buscaba evitar el fraccionamiento excesivo de la Cámara, como decía la norma, pero acaso también facilitar que fueran los partidos nacionales y no los nacionalistas los que contaran para la formación y estabilidad de los Gobiernos; podría bastar para ello la existencia de cuatro partidos de sólida implantación nacional, como parecía que iba a haber, aparte de otros menores.

4..$\left.^{\circ}\right)$ Y con la opción por la circunscripción provincial con una cuota fija de escaños se buscaba que fueran los más moderados de la derecha y de la izquierda, preferentemente los primeros, los hegemónicos en las coaliciones gubernamentales, puesto que quedaban sobrerrepresentadas las provincias menos pobladas, que suelen estar menos desarrolladas ${ }^{19}$, de las que se esperaba un voto en torno al centro-derecha o al centro-izquierda.

Como veremos más adelante, casi todo esto se cumplió, excepto lo concerniente al protagonismo de los partidos nacionalistas periféricos en la vida nacional.

\subsection{Primera formación del sistema de partidos}

El desconocimiento que los españoles teníamos de casi todo lo referente a elecciones y partidos, hacía que cupiera esperarlo casi todo. No todo, porque se suponía que el Gobierno alcanzaría mejores resultados, aunque solo fuera por ser

${ }^{19}$ Hay excepciones, como la de Álava. 
conocido por la mayoría del pueblo español, en tanto que a las fuerzas que habían sido Oposición en el exilio, en la cárcel o en la clandestinidad únicamente las conocían los adictos. Pero eso no era conocimiento, sino suposición. En realidad, había bastantes incógnitas, que versaban principalmente sobre:

- la fuerza de arrastre de UCD, partido constituido a última hora en torno al Presidente del Gobierno Adolfo Suárez, aunque se hiciera sobre los cimientos de Centro Democrático formado unos meses antes por Areilza y Cabanillas;

- la fuerza real del comunismo en España después de haber sido la pieza fundamental de la oposición al franquismo durante varias décadas:

- cómo se repartiría el voto socialista entre sus diversas versiones, que cerca de las elecciones quedaron reducidas a tres;

- la Democracia Cristiana, a la que J. LINZ daba como una e las fuerzas ganadoras, pero que también se presentó dividida: un sector, menos conocido, se integró en UCD y otro, con nombres ilustres y, por lo que se vio más tarde, algo gastados, liderado por Ruiz-Giménez y Gil-Robles;

- la cuota electoral que iban a conseguir los partidos nacionalistas, etc.

Al final sucedió lo lógico, como casi siempre en las elecciones generales en España. Bien es verdad que decir que los resultados electorales de 1977 fueron los esperados equivaldría a la impertinencia de profetizar el pasado. Pero sí puede sostenerse que, vistos a posteriori, solamente parecieron llamativas las abultadas diferencias entre PSOE y PCE, por un lado, y de UCD y AP, por otro.

El redactor del decreto-ley había acertado. De pronto nos encontramos con que la denostada «sopa de letras» había quedado en:

- cinco partidos de ámbito nacional, de los cuales dos (los más centrados) aventajaban claramente a los dos más extremos; y todos ellos por delante del Partido Socialista Popular;

- sendas fuerzas nacionalistas de bastante entidad en sus respectivas circunscripciones, aunque no hegemónicas;

- algunos partidos pequeños en Euskadi, Cataluña, Castellón (cuya vida se redujo a la legislatura constituyente) y Aragón (de aparición intermitente en el Congreso de los Diputados).

El parecido con Francia era notable, si hacemos abstracción de las peculiaridades que representan los partidos nacionalistas y la nota episódica del PSP, siendo así que el país de referencia tenía por aquel entonces, y ha vuelto a tener, un sistema de mayoría. Por lo demás, en Cataluña y en el País Vasco se reproducía con bastante aproximación el mismo esquema, sólo que el reparto de 
escaños se ventilaba entre dos conjuntos diferentes de partidos: CiU-PSOE y PNV-PSOE, principal y respectivamente.

Ése fue el resultado externo y «oficial». Pero hubo datos internos muy interesantes para nuestro estudio porque denotan la distorsión de la proporcionalidad en las primeras elecciones celebradas bajo este sistema y su mantenimiento desde entonces en términos generales (véanse en el cuadro número 1 las diferencias entre los porcentajes de votos y escaños en las elecciones desde 1977 hasta 2004):

a) UCD obtuvo una sobrerrepresentación extraordinaria del $37 \%$, traducida en 44 escaños, de manera que con un magro $34{ }^{\prime} 52 \%$ de votos casi alcanzó la mayoría absoluta.

b) PSOE tuvo una prima de 16 escaños, equivalente a una sobrerrepresentación del 15’3\%.

c) Los tres partidos menores de ámbito nacional sufrieron una fuerte «penalización» (quiérese decir subrepresentación): el PCE, del 37\% (12-13 escaños), AP del 45\% (13 escaños) y el PSP del 61\% (10-11 escaños).

d) La izquierda (PSOE, PCE-PSUC y PSP) tuvo mayoría de votos, y la derecha (UCD y AP), mayoría de escaños.

e) Como puso de relieve tempranamente M. MARTÍNEZ SOSPEDRA, de las 32 provincias sobrerrepresentadas, ni una sola votó mayoritariamente a la izquierda y 28 votaron a la derecha ${ }^{20}$; en ellas se fraguó la mayoría relativa de UCD en sufragios y, mucho más acentuadamente, en escaños.

Como dice el autor citado comentando este hecho, la desigualdad siempre beneficia a alguien ${ }^{21}$. A lo que cabe añadir que, como resulta manifiesto, este sistema electoral favoreció indisimuladamente a quien lo redactó. Es en las 28 circunscripciones que ponen en litigio menos de seis escaños, lo que significa un tercio del total en disputa, donde se adquiere o se refuerza ventaja de los dos primeros partidos.

Un notable protagonista del proceso constituyente, O. ALZAGA, escribió años más tarde al respecto unas palabras que confirman la conclusión que hemos extraído del análisis electoral que antecede. Dice así:

«El sistema preelectoral español es absolutamente original... y es bastante maquiavélico.... Porque la ley actual es esencialmente una reproducción del Decreto-ley del 77, y tal Decreto, formalmente pactado por el Gobierno prede-

${ }^{20}$ Martínez Sospedra, M.: «Desigualdad y representación en la Constitución española de 1978: el caso de las Cortes Generales», ob. cit., págs. 196-211.

${ }^{21}$ Ibidem, pág. 189. 
mocrático con las fuerzas de la oposición, fue elaborado por expertos, entre los cuales tuve la fortuna de encontrarme, y el encargo político real consistía en...formular una ley a través de la cual el Gobierno pudiese obtener mayoría absoluta. Puesto que los sondeos preelectorales concedían a la Unión de Centro Democrático un 36-37\% de los votos, se buscó hacer una ley en la que la mayoría absoluta pudiese conseguirse con alrededor del $36-37 \%$. Y con un mecanismo que en parte favorecía a las zonas rurales, donde en las proyecciones preelectorales UCD era predominante frente a las zonas industriales, en las que era mayor la incidencia del voto favorable al Partido Socialista (...) se procuraba que el logro de la mayoría absoluta para el Partido Socialista estuviera situado no en el 36$37 \%$, sino en el $39-40 \%$. $^{22}$

No obstante, evocando el principio de incertidumbre mentado al comienzo de estas cuartillas, me parece poco seguro que este notable texto responda a la realidad histórica. Si fuera así, no se entendería que UCD se resistiera durante el proceso constituyente, precisamente por boca del mismo autor, a constitucionalizar un sistema que había diseñado a medida, constitucionalización que sólo aceptó a última hora en aras del consenso con el PSOE.

El sistema había beneficiado, en efecto, a quien lo diseñó, pero había otros datos menos alentadores que hacían temer a UCD quedar en minoría, a saber:

- los votos de la izquierda superaban a los de la derecha y la sombra del frentismo se representó ante muchos protagonistas políticos;

- desapareció la Federación Demócrata Cristiana, que obtuvo votos en todas las circunscripciones pero no alcanzó ningún escaño;

- era más que evidente la inmediata absorción del Partido Socialista Popular (PSP) por el PSOE luego de resistirse a ello durante la legislatura constituyente;

- no parecía inviable el entendimiento entre éste y el Partido Comunista, como quedó confirmado unos meses más tarde en las elecciones municipales de abril de 1979, en el que ganaron las principales alcaldías de España, incluidas las de Madrid y Barcelona;

- igualmente previsible era la mejor concertación de los partidos nacionalistas con la izquierda por las posiciones que ésta mantenía favorables a la federalización del Estado.

22 Alzaga Villaamil, O.: «I rapporti tra Capo dello Stato, Governo e Parlamento», en Giancarlo Rolla (ed.): Il X aniversario della Costituzione spagnola: bilancio, problema, prospective, Centro Stampa della Facoltá di Scienze Economiche i Bancarie, Siena, 1989, págs. 127-128. 
De modo que, si UCD finalmente aceptó la constitucionalización del sistema hasta entonces vigente, fue sin entusiasmo y porque el consenso se había construido sobre mil cuestiones que no se debían malograr. Se confió, a mi juicio acertadamente, en que ni la España de fines del siglo XX era la del primer tercio del mismo, ni las fuerzas políticas presentaban un perfil tan aristado, ni el concierto internacional se parecía al de los años treinta, ni los partidos extranjeros homologables a los españoles, en cuya financiación participaban, propendían precisamente a las aventuras.

Como los resultados arrojados por las elecciones de 1979 fueron sustancialmente iguales a los de 1977 (con una nueva prima para UCD del 37\%, equivalente a 46 escaños, aún mayor que la de 1977), no faltaron analistas que dieron por definitivamente asentado el sistema español de partidos. Únicamente había que anotar la emergencia del Partido Socialista de Andalucía, con cinco escaños, la consecución de tres por parte de Herri Batasuna y la de algunos escaños sueltos por sendas formaciones, como Unión del Pueblo Canario (más tarde Coalición Canaria), Unión del Pueblo Navarro y Alianza del 18 de Julio (que no sobrevivió a la legislatura).

El iter de nuestro sistema electoral arrancó, pues, en la Ley para la Reforma Política, siguió con el Decreto-ley Electoral de 17 de marzo de 1977, se consolidó en el artículo 68 de nuestra norma suprema y fue regulado por extenso en la vigente Ley Orgánica del Régimen Electoral General (LOREG), a la que nos referiremos en páginas ulteriores. Los elementos esenciales del sistema no han variado desde su primer momento. La LOREG regula todas las fases del proceso electoral comunes a todo tipo de comicios que se celebren en España con la salvedad de las especificidades introducidas por las Comunidades Autónomas en su normativa electoral, a saber, el "tamaño» de la Asamblea Legislativa, la circunscripción electoral y la barrera electoral.

\section{EVOLUCIÓN POSTERIOR}

\section{1. ¿Sistema o subsistemas electorales?}

Cuando hablamos del sistema electoral español, en singular, estamos escribiendo en prosa sin saberlo; esto es, introducimos en nuestra exposición una clara sinécdoque por cuanto tomamos la parte por el todo, concretamente estamos hablando del sistema electoral español como si sólo hubiera uno: el establecido para el Congreso de los Diputados. 
Pero realmente son varios los sistemas electorales vigentes en nuestro país, porque en cuanto se cambia un elemento importante del mismo, el resultado es otro sistema diferente, aunque sólo sea en parte y aunque se produzcan resultados similares. Asumido lo anterior, en España se pueden identificar, en una primera aproximación, los siguientes subsistemas electorales, algunos de los cuales están muy próximos entre sí:

a) Un sistema nacional para el Congreso de los Diputados, excepto en Ceuta y en Melilla.

b) Un sistema para las elecciones al Congreso de los Diputados en Ceuta y en Melilla.

c) Un sistema nacional para el Senado, excepto en Ceuta y en Melilla.

d) Un sistema para las elecciones al Senado en Ceuta y en Melilla.

e) Un sistema nacional para los más de 8.000 Ayuntamientos y para las instituciones de gobierno de Ceuta y de Melilla.

f) Un sistema nacional para el Parlamento Europeo.

g) 17 sistemas electorales para los Parlamentos autonómicos, o, mejor, un sistema electoral autonómico con 17 variantes.

Por su parte, dos de los rasgos más llamativos de los subsistemas electorales autonómicos españoles son, de un lado, la imposición constitucional de que fueran proporcionales, y, de otro, la «autoarmonización» producida en buena hora por las propias Comunidades Autónomas, actitud plenamente consciente, querida y que algunas de sus leyes electorales justifica por la costumbre de los electores de votar con dicho sistema. Con lo cual, salvadas algunas especialidades, los diecisiete subsistemas electorales autonómicos son casi iguales entre sí y todos ellos muy similares al subsistema electoral para el Congreso.

Por último, aun con algunas diferencias importantes, el funcionamiento de los diecisiete ha sido parecido, con sus virtudes y sus vicios, al del modelo que les sirvió de referencia.

\section{2. ¿Sistema o subsistemas de partidos?}

Inmediatamente de celebradas las elecciones generales de 1979 se celebraron municipales y, aunque los resultados fueron similares a los de aquéllas, se pudieron observar ciertos rasgos que desde entonces no han cesado de asomarse con diferente grado de persistencia:

$\left.1 .^{\circ}\right)$ El ciudadano español comenzó votando de forma parcialmente diferente según la índole (municipal, autonómica o general; también puede 
apreciarse en las elecciones al Parlamento Europeo). Este primer rasgo, detectado en las primeras elecciones, se ha visto últimamente muy atemperado por otro de signo contrario: la fidelidad a una candidatura. Volveremos después sobre ello.

$\left.2 .^{\circ}\right)$ Como las circunscripciones municipales son mayores que las provinciales — valga la paradoja, que no lo es_- el "comportamiento» del sistema proporcional fue (y así ha venido siendo desde entonces) mucho mejor que en las elecciones generales.

3..$^{\circ}$ En el ámbito municipal (se repitió posteriormente en el autonómico) se conciertan Gobiernos de coalición, lo que ha favorecido generalmente a la izquierda. Esto significó en 1979 un más equilibrado reparto del poder entre la derecha (Gobierno central) y la izquierda (mayoría de los Ayuntamientos); a lo que deben sumarse los Gobiernos nacionalistas en el País Vasco y en Cataluña tras sus triunfos en las respectivas contiendas electorales autonómicas de 1980, en las cuales volvió a «funcionar» mejor el sistema electoral por la misma razón de la mayor dimensión de las circunscripciones.

De este modo teníamos un sistema de partidos más complejo de lo que parecía tras las generales. Más bien teníamos tres subsistemas: el vasco, el catalán y el del resto de España. Éste último, por razones obvias, es el que determina la formación del Gobierno central, pero no ha dejado de tener influencia en él la existencia de los otros dos subsistemas.

El deterioro de UCD y el frustrado golpe de Estado del 23 de febrero de 1981 marcaron a nuestro país también en la materia que estudiamos. Las elecciones generales de 1982 significaron, más allá de algunos pormenores numéricos, la aparición de otras dos variables, o una sola con dos vertientes (de momento), relativa al comportamiento electoral del ciudadano español: el elector español aprendió a utilizar su voto de modo calculado.

En efecto, la repetición de resultados en las dos primeras elecciones nos persuade de que la motivación del ciudadano-elector fue la de expresar su ideología y ayudar a la formación política más cercana a sus propias posiciones políticas a ocupar una posición adecuada para ejercer el poder o para influir en él. A partir de 1982, su comportamiento estuvo informado en parte no desdeñable por la «utilidad» de su voto. Sobre este punto volveremos más adelante, en el epígrafe 11.

Cuando en 1985 se elaboró la LOREG, en vez de corregirse algunos defectos del sistema puestos de manifiesto en tres convocatorias generales ${ }^{23}$, en una o

231977,1979 y 1982. 
dos autonómicas ${ }^{24}$, según los casos, y en dos municipales ${ }^{25}$, lo mantuvo tal cual, sin la más mínima modificación de sus elementos sustanciales. Lo más relevante fue su aprobación casi por unanimidad (solamente dos abstenciones y dos votos en contra); votaron a favor incluso los perjudicados, lo que no deja de ser llamativo. Pues bien, cuando en las inmediatas elecciones (1986) el PSOE obtuvo mayoría absoluta holgada con el $44 \%$ de los votos, se oyeron quejas acerca de la injusticia de la Ley. Se quejaron algunos de los que la habían aprobado casi por unanimidad un año antes.

A partir de entonces, el subsistema nacional de partidos pareció asentarse un tanto, pero lo cierto es que ha experimentado diversas inflexiones que lo han ido disponiendo en torno al eje derecha-izquierda y acentuando su tendencia a un cierto cuasibipartidismo, todo ello con la adición de los partidos nacionalistas. Cabe apuntar los siguientes movimientos ${ }^{26}$ :

1) Desaparición de UCD, sustituida en el centro-derecha por Alianza Popular, la cual fue refundada más tarde como Partido Popular con la consiguiente inexistencia de un partido que se identifique con una derecha estricta.

2) La emergencia y desaparición del Centro Democrático y Social, liderado por Adolfo Suárez, cuyos votos se han dividido entre PP y PSOE.

3) Altibajos en la formación situada a la izquierda del PSOE, primero en el PCE y después en Izquierda Unida, con tendencia a su decrecimiento. Sus votos han engrosado en parte los del PSOE y en parte la bolsa de abstención o lo que se ha denominado «izquierda volátil».

4) La consistencia de los partidos o coaliciones nacionalistas mayores (CiU y PNV), con suave tendencia última a la baja.

5) La aparición y la suerte varia en la política nacional de algunos partidos nacionalistas menores y de otros autocalificados como nacionalistas, aunque sean más propiamente regionalistas.

a. La presencia fugaz del Partido Socialista de Andalucía, más tarde llamado Partido Andalucista.

${ }^{24}$ Dos en Cataluña, País Vasco, Galicia y Andalucía; una en las demás Comunidades Autónomas.

251979 y 1983.

26 Cfr. SAni, G., y GunTHer, T.: «¿Qué hubiera pasado si...?: el impacto de la normativa electoral», en LinZ, J. J., y MonTERO, J. R. (eds.): Crisis y cambio: Electores y partidos en la España de los años ochenta, Centro de Estudios Constitucionales, Madrid, 1986, págs. 125 ss. 
b. La aparición de Coalición Canaria en el lugar de Unión del Pueblo Canario y su permanencia desde entonces.

c. Los avatares internos del Bloque Nacionalista Gallego, que parece haber logrado una cuota, reducida pero permanente, de presencia parlamentaria en el Congreso.

d. Declive, escisión, ascenso y nuevo descenso de Esquerra Republicana de Cataluña.

e. La ilegalización de Herri Batasuna y su sustitución por formaciones políticas sucedáneas, igualmente ilegalizadas o en trance de ello, con la incógnita del reacomodo de sus votos en el futuro.

Se me dirá que no son pocos esos movimientos, pero, salvo el primero y el tercero, los demás han sido un tanto epidérmicos y no han tenido una gran significación en el sistema de partidos, o, mejor, en la correlación de fuerzas entre derecha e izquierda, centro y periferia y partidos de implantación nacional y nacionalismo.

En fin, sobre todo, por lo que a nosotros nos interesa, es la orientación del llamado voto útil hacia los dos grandes partidos de implantación nacional, PSOE y PP, lo que se ha constituido en eje de todo análisis político.

\subsection{El inencontrable pluripartidismo del sistema politico nacional}

No ha aparecido, pues, la atomización partidaria que algunos temieron en el orto del sistema. De la irónicamente denominada «sopa de letras», vilipendiada por supervivientes del monismo franquista, no queda ni rastro. Bien es verdad que en España hay registrados unos 2.000 partidos políticos, pero ni esta cifra expresa la existencia real de tantos, ni, aun siendo muchos, consiguen escaños más de una docena ${ }^{27}$ y solamente dos con perspectivas razonables de alcanzar la formación de un Gobierno en solitario o con apoyo parlamentario, de lo que es buena ilustración que esté aún por experimentar un Gobierno nacional de coalición.

Digo una docena por hablar genéricamente de todos los tipos de elecciones. Pues, efectivamente, tampoco en las elecciones autonómicas han proliferado los partidos con efectivos parlamentarios, siendo muy frecuentes las Asambleas Legislativas bipartidistas y tripartidistas ${ }^{28}$, pese a las muy idóneas condiciones téc-

27 Once en la presente legislatura, o doce si se considera al Partido Socialista de Cataluña como diferente del PSOE. Sobre UPN y su relación con el PP no es aventurado decir algo en estos momentos. 
nicas para alcanzar una óptima proporcionalidad y, en función de ello, propiciar la emergencia de nuevas formaciones políticas. No ha habido tal y no es previsible que a corto o a medio plazo vaya a variar mucho esta característica de nuestro sistema electoral y de partidos.

De manera que, si una tendencia se observa en el elector español es la de ir concentrando sus votos en unos pocos partidos, justo los que pueden formar Gobierno o pueden ayudar a ello, o, en fin, pueden oponerse con eficacia y con perspectivas de alternancia política. Del resto se encarga el propio sistema con la prima electoral que otorga a unos y la penalización que impone a otros.

\section{INTERMEDIO: SISTEMA ELECTORAL Y DE PARTIDOS DE LAS COMUNIDADES AUTÓNOMAS}

Aunque el Seminario quiere centrarse en el sistema electoral vigente para las elecciones al Congreso de los Diputados, interesa que nos detengamos un tanto en el sistema o sistemas electorales autonómicos en aras de la advertencia que hicimos en las primeras líneas de esta ponencia. Como vamos a comprobar, nos espera la sorpresa de que, operando en ellos el sistema proporcional en mejores condiciones que en las elecciones al Congreso de los Diputados, tampoco ha tenido como consecuencia la aparición de un pluripartidismo extremo en la política autonómica, menos aún de una atomización en la composición de sus respectivas Asambleas Legislativas.

Éste es un extremo que merece reflexión porque acaso venga a indicarnos un cierto perfil del comportamiento del electorado español que busca esa conformación del sistema o sistemas de partidos, en cuyo caso contribuiría a reforzar la impresión que hayamos podido extraer del análisis anterior. Me referiré muy resumidamente a ello.

\subsection{Rasgos principales}

a) Constitucionalización y «autoarmonización» de la normativa electoral autonómica

El artículo 152.1 de la Constitución ha establecido en el máximo nivel normativo tres elementos del o de los sistemas electorales autonómicos: el su-

\footnotetext{
${ }^{28}$ Se me excusará que tome los grupos parlamentarios por partidos. Son, ya lo sé, asociaciones diferentes pero, como suelen corresponderse ideológicamente y en sus efectivos personales, cabe asimilarlos grosso modo (cfr. mi trabajo «Los grupos parlamentarios», RDP, n. ${ }^{9}$ 9, Madrid, 1980).
} 
fragio universal, la fórmula proporcional y la garantía de representación de las distintas zonas del gterrit0orio de la Comunidad.

A partir de ahí, los Estatutos de autonomía y las leyes electorales autonómicas ha procedido a dar cumplimiento a las previsiones constitucionales y a ultimar el diseño de sus respectivos sistemas electorales, que han terminado siendo muy semejantes al vigente para el Congreso de los Diputados. Esta actitud fue, por lo demás, plenamente consciente, querida y así explicada en los preámbulos de esas leyes con el argumento de que el electorado estaba ya acostumbrado a votar con un sistema (el del Congreso) y era conveniente continuar con él. Con lo cual, salvadas algunas peculiaridades, los diecisiete subsistemas electorales autonómicos son casi iguales entre sí y todos ellos casi iguales al subsistema electoral general.

Naturalmente, la promulgación de los nuevos Estatutos de Autonomía, por cuanto estos alteran las normas electorales vigentes, comporta la necesidad de revisar la legislación autonómica electoral ${ }^{29}$. Pero esto ya escapa al objeto de este trabajo.

b) Sobrerrepresentación y subrepresentación territorial

Los legisladores autonómicos han adoptado la misma decisión del legislador orgánico de atribuir a las circunscripciones menores una cuota fija de escaños antes de distribuir los demás en proporción a las respectivas poblaciones. Algunos la han acentuado todavía más haciendo una interpretación generosa de la exigencia constitucional de que en los Parlamentos autonómicos estén representadas todas las entidades territoriales de la Comunidad. Huelga decir que ello comporta la sobrerrepresentación de las circunscripciones menores y la subrepresentación de las mayores y, consiguientemente, que, hablando en términos globales, en las elecciones autonómicas existe una desigualdad del voto ciudadano aún mayor que en las generales, porque, como es sabido, a mayor igualdad de escaños entre circunscripciones muy dispares, mayor desigualdad de voto.

c) Magnitud idónea de las circunscripciones electorales para la proporcionalidad

Aunque los Parlamentos autonómicos no tienen un número excesivo de escaños, sí cuentan con los suficientes como para que las respectivas circuns-

29 Cfr. Martínez Sospedra, M.: «Sobre la necesidad de una ley electoral valenciana. (Los condicionantes constitucionales yn estatutarios de la ley electoral)", Corts, ADP, n. ${ }^{\circ}$ Valencia, 2007, págs. 121 ss. 
cripciones electorales tengan dimensiones idóneas para la práctica del sistema proporcional. De hecho, sólo hay siete circunscripciones pequeñas debido a sus especiales condiciones geográficas, y la mayoría son circunscripciones grandes, como refleja el siguiente resumen numérico:

- Número de circunscripciones en las elecciones autonómicas: 64.

- Circunscripciones pequeñas: 7

- Circunscripciones medias: 12.

- Circunscripciones grandes: 45 :

De entre 11 y 20 escaños: 27 .

De entre 21 y 30 escaños: 7 .

De más de 30 escaños: 11.

\subsection{El inencontrable pluripartidismo autonómico}

En un epígrafe anterior nos permitíamos dudar de que, pese a que las leyes electorales autonómicas han mimetizado el modelo electoral vigente para el Congreso de los Diputados, se tratara del mismo sistema electoral. La variación elocuente de un elemento tan fundamental como es la dimensión de las circunscripciones permite hablar de un sistema distinto. Lo que está todavía por ver es si arroja resultados también distintos y, en caso negativo, como así resulta ser, debemos buscar una explicación satisfactoria.

Pues bien, la respuesta que nos da otra de las claves que vamos buscando en nuestro análisis es doble:

a) El sistema proporcional funciona evidentemente mejor en las elecciones autonómicas que en la generales.

b) Frente a lo que cabría esperar conforme a estereotipos incuestionados por la Sociología Electoral durante mucho tiempo, esta mejor proporcionalidad no ha facilitado la fragmentación de las Asambleas Legislativas superior al que se aprecia en el Congreso, sino que en las Comunidades Autónomas se ha reproducido, hasta cierto punto, el subsistema nacional de partidos.

Lo más frecuente, salvo en el País Vasco, Cataluña y Baleares, es que los partidos con escaño se reduzcan a tres o a dos, incluso en circunscripciones de más de 10 escaños, que son casi todas, y de más de 20, que son quince. No ha habido, pues, fragmentación y no es previsible que vaya a haberla a corto o a medio plazo. 
El caso más llamativo es Madrid, que, con 120 escaños en litigio y con una proporcionalidad que alcanza centésimas en su aproximación a la exactitud (exactitud nunca alcanzable porque los escaños no son divisibles), sólo cuenta en su Asamblea Regional con tres formaciones políticas (PP, PSOE e IU), una de las cuales está muy por debajo de las otras dos ${ }^{30}$.

Hay Comunidades, como Andalucía y Castilla y León, que tienen ocho o nueve provincias con notables diferencias entre ellas, tanto económicas como de magnitud electoral. Pongamos como ejemplos no únicos Sevilla y Huelva, de un lado, y Valladolid y Zamora, de otro. Lo mismo podría decirse de alguna otra Comunidad Autónoma, como Galicia, con dos provincias más pobladas y desarrolladas (La Coruña y Pontevedra) y otras dos menores en ambos aspectos (Orense y Lugo). Pues bien, en ninguna de esas provincias se pasa de dos partidos con escaño (en Castilla y León) o de tres (en Andalucía ${ }^{31}$ y en Galicia).

También podría esperarse que, por el carácter regional de estas elecciones, tendrían en ellas buenas oportunidades partidos de esta índole, en los que el electorado acaso pudiera depositar su confianza para gestionar intereses cercanos cuyas competencias han sido asumidas por los correspondientes Estatutos de Autonomía. Tampoco ha sucedido. Los partidos de exclusiva implantación autonómica que obtienen buenos resultados, incluso aptos para formar Gobierno por sí solos o en coalición, son CiU y ERC en Cataluña, PNV en el País Vasco, CC en Canarias, PRC en Cantabria y BNG en Galicia. Pero estos partidos no son propiamente regionalistas, sino nacionalistas. $\mathrm{Y}$ todos ellos suelen tener mejores resultados en las elecciones autonómicas que en las nacionales. De la tensión antes enunciada entre votar diferente en las elecciones autonómicas y votar preferentemente a los dos grandes partidos nacionales, la primera sigue resistiendo a la segunda en Euskadi y en Cataluña, aunque con tendencia reciente a la baja.

En síntesis,

a) hay bipartidismo estricto, o bien escoltado por algún tercer partido o incluso cuarto, que solamente en ocasiones han participado en un Gobierno de coalición en nueve Comunidades Autónomas: Murcia, Castilla La Mancha, Extremadura, Castilla y León, La Rioja, Andalucía, Valencia, Aragón y Asturias.

30 Por el contrario, en las últimas elecciones generales fueron cuatro los partidos que alcanzaron escaño, bien que el dato resulte anecdótico o provisional porque ese cuarto partido (UPyD) fue creado justo en vísperas de dichas elecciones.

31 Durante mucho tiempo, han sido cuatro. Está por ver si el hundimiento del Partido Andalucista en las elecciones de 2008 es o no pasajero. 
b) Hay un sistema de tres partidos, en el que, el menor (o el de ámbito no nacional) ha tenido con alguna frecuencia o tiene responsabilidades de Gobierno en cuatro Comunidades: Madrid, Galicia, Cantabria y Canarias.

c) En dos Comunidades hay pluripartidismo, aunque con los dos partidos de implantación nacional como alternativamente hegemónicos para gobernar en solitario o en coalición: Navarra y Baleares.

d) Comunidades pluripartidistas, con partidos de implantación nacional y varias formaciones nacionalistas, son otras dos: Cataluña y País Vasco.

A todas luces, éste es un resultado llamativo que requiere una revisión del análisis incluyendo en él algún otro elemento convergente del sistema electoral. Intentamos una aproximación a ello en el epígrafe siguiente.

\section{HOMOGENEIZACIÓN DEL COMPORTAMIENTO DEL ELECTORADO EN LAS ELECCIONES GENERALES Y AUTONÓMICAS.}

Falla, pues, la teoría más tópica de la Sociología Electoral acerca de la «natural» desembocadura del sistema electoral proporcional en un pluripartidismo si las circunscripciones son idóneas. La explicación de esta quiebra de una de las tesis más tópicas de la Sociología Electoral hay que buscarla sea en que la ciudadanía española no es ideológicamente tan plural como parecen indicar los casi 2.000 partidos registrados en el Ministerio del Interior, sea en motivaciones del comportamiento electoral, tales como:

1) la influencia de la política nacional en la regional, lo que se traduce en la mayor confianza que inspiran los partidos de implantación nacional también para gestionar los intereses regionales;

2) la tendencia al «voto útil», nota muy relacionada con la anterior.

Hay, en efecto, una fidelidad del electorado a «su» partido más alta de lo que usualmente se dice, lo que, en el conjunto de la nación, favorece a las dos formaciones políticas principales, PP y PSOE, que concentran el voto para sí en ambos tipos de elecciones. Por tanto, el voto flotante ocupa cada vez una franja más estrecha y, muy esquemáticamente expuesto, se integra por dos facciones: el trasvase de votos de doble dirección entre el Partido Popular y el Partido Socialista y la afluencia (con visos de ser definitiva) de votos de formaciones políticas menores a los dos partidos mencionados ${ }^{32}$.

${ }^{32}$ Hay más movimientos de votos, claro es; pero estos dos son seguramente los principales y el segundo es el que explica la tendencia al alza de dichos partidos «de Gobierno».

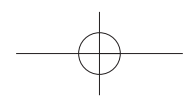


Convergiendo con lo anterior, en las elecciones autonómicas se percibe igualmente una tendencia al "voto útil», porque, excepciones aparte, sólo de unos pocos partidos se puede decir que opten seriamente a formar Gobierno o a influir seriamente en él. Lo cual ha contribuido igualmente, junto a otros factores, a lograr uno de los objetivos perseguidos desde el inicio de la transición: evitar el fraccionamiento excesivo de las Cámaras.

En cierto modo, este comportamiento viene a ilustrar que el modelo ideal de elector racional, que administra calculadamente su voto, va adoptando unas pautas de conducta similares a las de su parejo económico, el consumidor racional, que antes de gastar un euro estudia detenidamente las condiciones del mercado. El elector racional es menos concienzudo, no actúa consultando programas y diferenciando entre las elecciones a las que se le convoca, pero tampoco quiere "perder» su voto entregándolo a una candidatura que ni siquiera tiene opción de entrar en el reparto de escaños.

Después del recorrido hecho hasta aquí se comprende que, a pesar de que el número de partidos inscritos en el Registro del Ministerio del Interior sea tan elevado, los que obtienen escaños parlamentarios sean solamente una docena, a veces menos, y los que logran constituir un grupo parlamentario, únicamente siete u ocho, también a veces menos ${ }^{33}$. Por esta vía queda racionalizado el multipartidismo, reduciéndolo a unas pocas ofertas políticas creíbles con tendencia a alinearse en torno a dos programas de gobierno. Pues, en efecto, durante treinta años, sólo dos partidos han estado, en cada ocasión electoral, en condiciones de formar Gobierno, y algunas veces, nada más que uno ${ }^{34}$. Lo que subraya la tendencia "cuasibipartidista» del sistema político español, que a veces ha llegado a ser de partido hegemónico.

De manera que, si una tendencia se observa en el elector español es la de ir concentrando sus votos en unos pocos partidos, justo en los que pueden formar Gobierno, ayudar a ello u oponerse con eficacia y con perspectivas de alternancia política. Y, acaso de una manera sorprendente, dicha tendencia se acentúa en las elecciones autonómicas.

${ }^{33}$ En la actual legislatura, solamente cuatro partidos cumplían los requisitos en el Congreso de los Diputados, pero una interpretación benévola del Reglamento parlamentario ha facilitado la formación de un quinto grupo de composición heterogénea.

34 Así, de 1977 a 1982, dada la gran diferencia de escaños entre UCD y PSOE, y de 1982 a 1993, porque el PSOE obtenía mayoría absoluta, o el 50 \% de los escaños, y AP o PP quedaban a 50, 60 e incluso 80 escaños de distancia, lo que le cercenaba toda posibilidad de gobernar; de nuevo, en la VII legislatura (2000-2004), en la que solamente el Partido Popular, con mayoría absoluta y una gran diferencia (de casi 60 escaños) sobre el segundo partido, el PSOE, podía formar Gobierno. 


\section{ABANDONO DE LA OPCIÓN INICIAL DEL SISTEMA: EL MAL BIPARTIDISMO Y EL BUEN PLURIPARTIDISMO.}

Los recelos y las quejas que se oyen actualmente son muy diferentes de los que durante la transición a la democracia nos advertían de los males del sistema proporcional: el excesivo pluripartidismo y aun la atomización de la representación política. Ahora apuntan en dirección contraria, a saber, que el sistema electoral funciona como un filtro demasiado estrecho que falsea la proporcionalidad, impide la emergencia de nuevos partidos y, en definitiva, fabrica artificialmente un pseudobipartidismo que está agostando nuestra democracia; incluso es el culpable de la corrupción, etcétera.

Quienes tal afirman extraen como consecuencia que la solución pasa por la incorporación de nuevas formaciones que enriquezcan la política española con sus proyectos, con su participación en los debates en el seno del Parlamento, con sus críticas y con la nuevas combinaciones que ofrecen para la gobernabilidad del Estado. Más todavía: significarían la mejor opción para liberar al partido gobernante que sólo tuviera mayoría relativa en el Congreso de la incómoda compañía de los partidos nacionalistas.

El buen pluripartidismo (moderado) y el mal bipartidismo (artificial) no deja de ser una tesis interesada y no contrastada con la realidad (ni con la estadounidense, ni con la inglesa, ni con la francesa, ni con la alemana); pero no es, ni jurídica ni políticamente, una simpleza. Es una posible deriva del sistema de partidos y del sistema político que seguramente tendría lugar según cómo se modificara el sistema electoral ${ }^{35}$.

Quedan, sin embargo, analistas que, por el contrario, participan de los principios que dieron vida al sistema y siguen viendo en la concentración del voto en pocos partidos y en el consiguiente cuasibipartidismo una de las características más positivas de nuestra legislación electoral. Lo basan en dos argumentos. En primer lugar, que ha permitido la dirección política del país por Gobiernos unitarios, aunque a veces con apoyos externos en el Parlamento,

35 Hasta ahora, los leves rasgos de multipartidismo español, que los hay, apuntan en sentido contrario: ¿cuál fue el principal obstáculo para la aprobación de los Presupuestos de 2006, 2007 y 2008? Dicho escollo, opuesto por ERC, no obedeció precisamente a discrepancias presupuestarias con el Gobierno, sino a motivos estatutarios. Unas declaraciones posteriores de dicho partido han separado la suerte de los dos envites políticos, lo que no está mal, pero nos obliga a malconocer la deriva de la política nacional leyendo todos los días declaraciones contradictorias en los periódicos. No es ése, desde luego, el multipartidismo que va a solucionar nuestros problemas. Y no creo, por ende, que debamos incrementarlo. 
desconociéndose «afortunadamente» entre nosotros los Gobiernos de coalición que padece Italia ${ }^{36}$. En segundo término, el sistema ha deparado, como consecuencia, una duración media de los Gobiernos parangonable con la alemana y muy superior a la italiana ${ }^{37}$.

\section{LOS PARTIDOS NACIONALISTAS}

\subsection{La no sobrerrepresentación de los partidos nacionalistas.}

Apenas hay una cuestión política española que no precise de una referencia a los partidos nacionalistas y a sus respectivas Comunidades Autónomas. La nuestra no escapa a tal designio y ya ha aparecido en páginas precedentes.

Los partidos nacionalistas protagonizan la vida política de sus respectivas Comunidades Autónomas y condicionan la vida política nacional. Por eso hay una corriente de opinión muy intensa y extensa que no sólo denuncia este dato del sistema político español, sino que también cree identificar su causa: un sistema electoral que los favorece y les permite tener una incidencia en la política superior a la que les correspondería por el volumen de sus votos.

Lo primero que hay que decir es que esta apreciación no es correcta. La traducción de los votos que alcanzan los partidos nacionalistas y regionalistas en escaños del Congreso de los Diputados ha sido bastante fiel al principio que informa un sistema proporcional, puesto que han logrado una representación parlamentaria nacional similar, con algún matiz, a los apoyos electorales recibidos. Tienen, pues, uno más uno menos, el número de escaños que les correspondería si el cómputo de los mismos y la distribución de escaños se hiciera en un colegio nacional único o por la fórmula de resto mayor, que pasa por ser la mas ajustada matemáticamente.

Al final, después de treinta años, se ha abierto camino la evidencia de que la desproporcionalidad de nuestro sistema electoral no beneficia a los partidos nacionalistas a costa de Izquierda Unida, y ahora también de Unión para el Progreso y la Democracia (UPyD). El propio dirigente de Izquierda Unida, Gaspar Llamazares, después de haberlo afirmado tras cada fracaso electoral, ha terminado aceptando en sus artículos y declaraciones de explicación o disculpa por los resultados de IU en las elecciones generales de 2008, que los escaños que le faltan no los tienen los partidos nacionalistas, sino el PSOE y el PP. Es bueno

${ }^{36}$ Italia aparece frecuentemente entre nuestra clase política como antimodelo, tanto ahora como durante la transición a la democracia.

37 NúNÉEZ-Rufino, R.: «A vueltas con el sistema electoral», El País, 30-4-2008. 
por eso que, si bien el mensaje todavía no ha calado suficientemente en la ciudadanía, el asunto comience a perder algo de morbo antinacionalista, lo que no es poco.

Así, pues, se está abriendo paso la convicción, mucho más correcta, de que el PSOE y el PP, como partidos de fuerte implantación nacional y dadas las características del sistema electoral español, son los grandes beneficiarios del mismo a costa de otros partidos que, estando también implantados en todo el territorio nacional, logran menos apoyo, por lo cual sus cocientes electorales en cada circunscripción no les permiten entrar en el reparto de escaños, perdiendo así los votos obtenidos en ellas.

Pero esto no es de ahora, sino que ha sucedido siempre, desde 1977 hasta la fecha. Los estragos del sistema también los padecieron Alianza Popular y el Partido Comunista, fuertemente penalizados una y otra vez, por no hablar de la suerte que corrieron en igual fecha la Unión Democristiana de Ruiz-Giménez y Gil-Robles, que no obtuvo ningún escaño, desapareciendo como proyecto político; el Partido Socialista Popular, liderado por Tierno, que lo condujo a dejarse absorber por el PSOE y no acudir a la convocatoria de 1979, y el Centro Democrático y Social desde su aparición en 1982 hasta su penoso deambular por las diversas convocatorias a partir de 1989.

Mientras tanto, en las dos primeras elecciones, Unión de Centro Democrático obtuvo un plus de escaños extraordinariamente generoso, como hemos visto, $y$, en mucha menor medida, también el PSOE. En las tres elecciones siguientes, el máximo beneficiado fue el PSOE, aunque menos que la UCD en su día y que AP/PP más tarde; y así sucesivamente.

En todas estas ocasiones, combinándose el azar con la necesidad y haciendo de ésta virtud, los partidos nacionalistas se han mantenido a la par. No porque el sistema se diseñara así de propósito, sino por la magia de los números, que determina que la prima que algunos de ellos (PNV y CiU) obtienen en sus circunscripciones y la penalización que sufren otros (ERC, EA) se diluyan en un supuesto y meramente académico cómputo nacional.

Como son los números los que mejor explican las cosas, conviene que nos fijemos en el cuadro número 3, en el cual se puede apreciar, entre otros pormenores, los siguientes:

- De entre los partidos nacionalistas, el más beneficiado ha sido siempre el PNV, que consiguió dos escaños más en 1977 y uno en 1979, 1982, 2000 y 2004.

— CiU obtuvo uno más en 1977 y uno menos en 1979, 1982 y 2004. 
- ERC sólo ha quedado a la par (aunque a la baja) en 2004: en todas las demás ocasiones ha sido penalizada en un escaño, y casi dos (por centésimas) en 1977, 1993 y 2000.

- Coalición Canaria ganó dos escaños más en 1996 y en las demás elecciones estuvo a la par.

- El BNG ha tenido un escaño menos en 1993, 1996 y 2000.

- Por último, porque prescindo en esta relación de grupos aún menores, HB tuvo un escaño menos en 1982 y 1993.

Apelando de nuevo a la magia de los números, obsérvese cómo, salvo en 1977, en ninguna otra convocatoria electoral ha coincidido que dos partidos nacionalistas hayan sido beneficiados con una prima de escaños y sólo en 1993 ocurrió lo contrario: que dos lograron escaños de menos. La conclusión es bien fácil: el problema de la desproporcionalidad del sistema electoral no reside aquí.

Más sentido parece tener la objeción que se ha escuchado tras las últimas elecciones, según la cual, aunque no obtienen más escaños que los que les corresponderían en un cómputo nacional, sí se benefician del perjuicio sufrido por otras fuerzas políticas para alcanzar un peso político en la gobernación del Estado superior al que podría corresponderles por sus votos, al menos en comparación con los partidos perjudicados ${ }^{38}$. Tanto peor cuanto que a los partidos nacionalistas no les interesa la política nacional sino en función de la de sus respectivos territorios, como evidencian no presentando candidaturas más que en ellos.

Dicha objeción, empero, es en realidad una repetición con palabras distintas de la tesis refutada anteriormente, puesto que persiste en ella el mismo desenfoque. Lo que tendría que decir es que quienes tienen esos votos y ese poder suplementario son el Partido Popular y el Partido Socialista Obrero Español y que, si la proporcionalidad del sistema fuera mejor, IU mejoraría su posición política para concertar pactos de legislatura en el seno de la izquierda, apoyos tácticos

${ }^{38}$ Es lo ocurrido en la V legislatura (1993-1996), con Gobierno socialista, que tuvo el apoyo de CiU y del PNV. Lo mismo sucedió en la legislatura siguiente, con Gobierno del Partido Popular, que contó con los mismos apoyos más el de Coalición Canaria, y nuevamente en la VIII legislatura, otra vez con Gobierno socialista e iguales apoyos. Por lo que se refiere a la legislatura actualmente en curso, el Gobierno socialista ha preferido negociar apoyos puntuales para cada proyecto de ley o episodio, si bien le falta el de Coalición Canaria, precisamente por desencuentros a la hora de formar Gobierno en el archipiélago tras las elecciones autonómicas de 2007. De todos modos, no debemos olvidar que ya el Gobierno de UCD buscó repetidamente iguales apoyos en la legislatura constituyente y en la primera constitucional. 
y estratégicos, o bien para ejercer fuerza opositora. Y otro tanto cabe decir ahora respecto de UPyD.

Pero, por eso mismo, una vez ajustada la objeción en los términos dichos, la reivindicación de una reforma electoral sigue siendo legítima, por complicada que resulte y por muchos inconvenientes políticos que algunos quieran encontrarle.

\subsection{La posición intocable de los partidos nacionalistas en el sistema electoral}

El hecho de ser el Partido Nacionalista Vasco y Convergència i Unió fuerzas políticas hegemónicas o casi hegemónicas en su respectiva Comunidad Autónoma les ha conferido, por ese mismo hecho, un peso importante en la política nacional, por cuanto la política de construcción del Estado autonómico se ha llevado, y continúa llevándose, con mucho equilibrio y consideración hacia estas fuerzas políticas. A este dato hemos de sumar el aún más decisivo de que, como hemos apuntado en el apartado anterior, esas mismas fuerzas han contado en el Congreso de los Diputados con los escaños necesarios y suficientes para completar los del partido ganador de las elecciones generales a la hora de formar Gobierno y de facilitarle la aprobación de los Presupuestos Generales del Estado y de las leyes más importantes de la legislatura, amén de garantizar la estabilidad de dicho Gobierno frente a la Oposición, a la que disuadía de la presentación de una moción de censura condenada al fracaso.

No cabe duda de que, vistos así, los partidos nacionalistas han contribuido, y no poco, a la gobernabilidad de un Estado que paradójicamente sólo les interesa para separarse de él, aunque sea en último extremo y a largo plazo. Pero este manifiesto servicio ha venido teniendo en la política de sus Comunidades Autónomas una -llamémosla así- traducción inversa también indisimulable. En efecto:

- PNV ha presidido siempre el Gobierno vasco, sin ser el partido más votado, ha logrado durante años ser considerado como absolutamente imprescindible en dicho Gobierno e incluso en su Presidencia. Esto es, ha creado una suerte de autoidentificación con el País Vasco y ha conseguido que prenda así en el imaginario popular.

- CiU, por su parte, ha gobernado Cataluña desde la restitución de la Generalitat hasta 2003. En la legislatura estatuyente de 2003 a 2006, estuvo en la Oposición, pero el Gobierno central prefirió pactar con ella el texto final del Estatuto de 2006, puenteando incluso al PSC-PSOE. Y es que también aquí ha germinado la idea, incluso en las más altas esferas del Go-

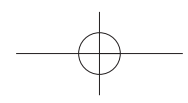


bierno de la nación, de que Cataluña no debe gobernarse sin CiU porque normalmente tampoco España puede gobernarse sin ella ${ }^{39}$.

Esta creencia política subliminal ha cedido muchos enteros en el caso del País Vasco, pero no en el de Cataluña y está pesando en toda la política nacional; para bien o para mal. Dicho de otro modo: han sido la solución y el problema, acaso por este mismo orden.

Consiguientemente, la posición de los partidos nacionalistas de cara a una eventual reforma electoral es muy consistente, puesto que, junto al dato cierto de que no obtienen ninguna prima de escaños en el sistema electoral vigente, su protagonismo en la vida nacional les hace sustentar una posición negociadora punto menos que inexpugnable. Hay, pues, que contar con ellos a la hora de modificar el sistema electoral, si es que alguna vez se acomete tal empeño. He aquí un pie forzado de toda operación reformadora; y eso significa que no tiene recorrido alguno el intento de modificar el sistema en un sentido que les sea adverso.

Pero, por decirlo todo, al anterior argumento político, que es discutible, como todo en política, se une un argumento ético para mí poco dudoso: no sería democrático manipular a conciencia el sistema electoral para perjudicar conscientemente a los partidos nacionalistas haciéndoles perder escaños por debajo de sus porcentajes nacionales.

\section{MAYORÍA DE VOTOS, MAYORÍA DE ESCAÑOS Y FORMACIÓN DE GOBIERNO, TRES EFECTOS ELECTORALES NO SIEMPRE SECUENCIALES ${ }^{40}$}

Como he escrito en otro lugar ${ }^{41}$, pertenece a los enunciados generales de la Sociología Electoral que en los sistemas de mayorías puede darse el supuesto de

39 Recuérdese la disidencia creada entre el actual Presidente de la Generalitat y el del Gobierno de la Nación a la hora de formar el Gobierno autonómico tras las elecciones de 2006, del que lo que interesa destacar aquí es la apuesta del Gobierno y del PSOE por incorporar a CiU al Ejecutivo catalán.

${ }^{40}$ Cfr. Pérez Sola, N.: «L’evoluzione del sistema dei partiti in Spagna»; y SÁIz Arnaiz, A.: "Coalizioni di governo e sistema parlamentare nel Paese Basco"; ambos en GAMBINO, S., y RUIZRICO RuIZ (coords.): Forme di governo, sistema elettorali, partiti politici: Spagna e Italia, Maggioli Editore, Rimini, 1996, págs. 179-224 y 467-492, respectivamente.

41 Torres del Moral, A.: «Sistemas electorales y sistemas de partidos de las Comunidades Autónomas», en GÁlveZ, L. (coord.): Derecho electoral de las Comunidades Autónomas..., ob. cit., págs. 228-229. 
que la obtención de más votos por parte de una candidatura se traduzca en un menor número de escaños que el obtenido por su adversaria. Casos se han dado en el Reino Unido y en las elecciones presidenciales de Estados Unidos, si bien en este último país hay que introducir en la ponderación el carácter indirecto de la elección. Y, por contra, se afirma igualmente como principio general, que eso no ocurre en los sistemas proporcionales, o que, en buena lógica, no debería ocurrir.

Sin embargo, ha ocurrido. Todavía no en las elecciones generales, pese a las excesivas correcciones de la proporcionalidad, pero estas mismas correcciones están poniendo las bases para que pueda suceder en el futuro. Incluso se especuló mucho sobre esa posibilidad en las últimas elecciones generales (2008) a la vista de las encuestas y los sondeos que manejaba el Partido Popular. No he tenido acceso a ellas, pero tampoco son necesarias para aceptar lo evidente. Desde 1977, la sobrerrepresentación alcanzada por la formación de centro-derecha ganadora ha sido siempre superior a la obtenida por la formación de centro-izquierda ganadora. Incluso en alguna ocasión en que ha ganado las elecciones el centro-izquierda, la sobrerrepresentación del centro-derecha se ha acercado mucho a la de su adversario. Sólo falta que se dé el paso siguiente: que la confluencia de una victoria escasa en votos a escala nacional de un partido con su derrota en las provincias más sobrerrepresentadas le depare menos escaños que al siguiente en votos pero vencedor en dichas provincias. Fenómeno que, por los datos disponibles hasta ahora, que pueden considerarse constantes, suficientes y poco menos que definitivos, únicamente puede ocurrir en beneficio del centro-derecha. Como ya vimos al principio de este estudio, quien diseñó el sistema sabía lo que hacía.

Pues bien, aunque el sistema proporcional ofrece mejores resultados en las elecciones autonómicas que en las generales, también en ellas se dan ciertas condiciones que puede facilitar en alguna ocasión el fenómeno descrito. Y, acaso inesperadamente, ha ocurrido antes en éstas que en aquéllas. Fue en las elecciones catalanas de 2000, en las que el Partido Socialista de Cataluña (PSC-PSOE) obtuvo más votos en toda la Comunidad Autónoma pero tres escaños menos que Convergència i Unió (CiU). La explicación reside, como se habrá adivinado, en la sobrerrepresentación de las circunscripciones de Girona, Lleida y Tarragona, caladero habitual de votos de esta coalición, y la consiguiente subrepresentación de la de Barcelona, donde el PSC suele obtener sus mejores resultados.

Por otra parte, tampoco existe una correlación entre el triunfo electoral, medido en votos y/o en escaños, y la formación de Gobierno por parte del partido en cuestión. Ciertamente nunca ha sucedido que tras unas elecciones generales haya formado Gobierno un partido que no haya obtenido más votos y más escaños que su inmediato competidor. Más aún: se ha extendido la práctica, que no me atrevo a elevar a la categoría de costumbre constitucional, de que tome la 
iniciativa para formar Gobierno el partido vencedor (que hasta ahora, como he indicado, siempre lo ha sido en votos y en escaños), iniciativa siempre coronada por el éxito. Naturalmente, de no triunfar en el empeño, el camino quedaría despejado para que lo intentara la segunda formación; pero, insisto, esto no ha sucedido hasta ahora.

Retengamos, no obstante, que la esencia del sistema parlamentario de Gobierno, como es el español, radica en la relación fiduciaria que liga al Gobierno con el Parlamento (entre nosotros, el Congreso de los Diputados), de manera que no se puede constituir aquél sin la confianza de éste y no se puede mantener si tal confianza quiebra. O lo que es igual: las elecciones generales al Congreso de los Diputados no se ganan propiamente en las urnas, sino en dicha Cámara, que es la que «interpreta» los votos populares.

$\mathrm{Y}$ en esto, de nuevo, la experiencia autonómica es más rica, como es de suponer porque se da en una proporción de diecisiete a uno. En una ocasión (Cataluña, 2000) tuvo ello lugar por el fenómeno anteriormente descrito: obtuvo más escaños el segundo en votos, el cual se encontró por eso en mejor posición de partida para formar Gobierno. Pero otras veces, con más o con menos votos, la formación política ganadora en escaños (que en eso consiste la victoria electoral en un sistema parlamentario) no logra formar Gobierno porque lo impide una alineación de otras dos o más fuerzas políticas ora para concertar un Gobierno de coalición (son los casos gallego y catalán de las presentes y respectivas legislaturas), ora para facilitar un Gobierno en minoría del segundo partido apoyado parlamentariamente por esa o esas otras formaciones, que es lo sucedido en Islas Baleares en las legislaturas V (1999-2003) y VII (2007-).

\section{CONCLUSIONES DEL ANTERIOR ANÁLISIS}

1. La tendencia observable en las elecciones generales es la del progresivo afianzamiento de un bipartidismo hegemónico. Salvo hundimientos temporales de uno de los dos grandes partidos, como sucedió al PSOE en 2000 (que cuatro años más tarde se vio que había sido pasajera) los dos grandes partidos suman cada vez más votos y más escaños, reduciendo consiguientemente el espacio de los demás. Se aprecia con nitidez en el cuadro número 3.

La misma tendencia se observa en las elecciones autonómicas, salvo en el País Vasco, Cataluña y Baleares, con caracteres específicos en cada una de ellas. Los sistemas de partidos autonómicos son todavía más sencillos que el nacional, pese a que las condiciones que ofrece el sistema electoral son propicias a la emergencia de un claro pluripartidismo. 
Este dato es un claro aviso a quienes intentan entrar en la brega política con partidos de nueva creación. Han de saber en qué país pretenden jugar: un país con un bipartidismo hegemónico que sólo quiebra débilmente aquí o allá, o de manera más seria en dos Comunidades Autónomas, País Vasco y Cataluña por la fuerza y, al mismo tiempo, la división que allí presenta el nacionalismo. De manera que ni siquiera con buenas condiciones de proporcionalidad salen a flote nuevos partidos con escasa fuerza competidora.

2. Hay cuatro constantes en el comportamiento electoral de los espanoles: su moderación, su conservadurismo, en el sentido que damos a este término en las líneas que siguen, su utilitarismo y su división a partes iguales o casi iguales entre los dos grandes partidos de implantación nacional.

2.a) Que es moderado parece obvio si reparamos en la suerte que han corrido las fuerzas situadas más a la derecha y más a la izquierda del espectro político. Las primeras han desaparecido y las segundas parecen llevar el mismo camino. Detengámonos un momento en este punto.

Es evidente que la ideología de extrema derecha no ha desaparecido, pero los partidos que mejor pudieran representarla como tal ideología sí han desaparecido a efectos electorales. Algunos se presentan a las elecciones, pero no obtienen respaldo alguno. Si bien se mira, esto significa que hasta el extremista de derechas se comporta electoralmente de forma algo más moderada de lo que cabía esperar y vota al Partido Popular. De otro lado, el trasvase de votos de IU al PSOE es una prueba de lo mismo. No es que yo diga que IU sea extremista de izquierdas. Digo sólo que el PSOE es visto como más centrado y se beneficia electoralmente de ello.

2.b) De manera que el PP se ha hecho con todos los votos de la derecha (nacionalismos aparte) y en la izquierda el PSOE está consiguiendo lo mismo, o, por decirlo más matizadamente, se va haciendo con buena parte de los votos que antes nutrían formaciones políticas a su izquierda (también nacionalismos aparte) y con casi todos sus escaños. Este dato de la moderación del elector puede ser llamado también utilitarismo.

Dicho de otra manera: el elector español es moderado porque tiende al voto útil, propende a influir el máximo posible sin traicionar demasiado su ideología. No se trata de que el sistema electoral español fuerce el comportamiento de los votantes; seguramente no es ésa la interpretación más precisa; mejor sería decir que parece sugerir al elector o persuadirlo de un comportamiento en aras de la utilidad del voto ${ }^{42}$, actitud que le ha llevado a:

${ }^{42}$ Ya sé que la expresión «voto útil» es poco grata para algunos, pero también creo que es muy expresiva y es entendida por todos de manera nada despectiva para nadie. Sencillamente, todo elec- 
1) ir retirando paulatinamente su voto a los partidos de menor implantación nacional a la vista de que en algunas circunscripciones ni siquiera tienen opción a entrar el reparto de escaños;

2) inclinarse bien por la abstención, bien por votar a partidos fuertes, que, aunque no les satisfagan plenamente desde el punto de vista ideológico o programático, tampoco les están muy alejados $\mathrm{y}$, en cambio, tienen a su favor su mayor entidad para formar Gobierno o para hacer oposición.

3) abandonar las formaciones políticas internamente divididas, indisciplinadas y ayunas de un liderazgo sólido como poco dignas de confianza política. Creo que sobran ejemplos.

Todo lo cual, de una manera u otra, ha permitido o estimulado la formación de un sistema de partidos que podríamos calificar de pluralismo atenuado o incluso, según hemos indicado más arriba, de un cierto bipartidismo.

Tomando en consideración esta nueva variable, se explican tres importantes movimientos en las elecciones generales de 1982, ya anotados anteriormente: el hundimiento electoral de UCD, que lo llevó a su desaparición ${ }^{43}$; el descenso también muy significativo del PCE, que a la larga hubo de buscar coligarse con otras formaciones en Izquierda Unida; y el voto masivo al PSOE, que se presentaba en dicha convocatoria electoral como el único partido de ámbito nacional unido tras un programa y un líder, el partido que mejor vertebraba España en aquellos momentos y que mejor podía hacer frente a la grave crisis provocada por el mencionado golpe de Estado. Esa imagen, más que consideraciones ideológicas y programáticas, le sirvió para ganar tres elecciones consecutivas, si bien de modo decreciente. Mientras tanto, la derecha, aunque reunida en torno a Alianza Popular, seguía sin crecer y un tanto desnortada. Pero le ocurriría asimismo al PSOE, en menor medida y por motivo similar, en la convocatoria de 2000.

En efecto, el elector quiere influir con su voto para que se forme el Gobierno que desea o, al menos, no muy alejado de lo que él quisiera, o para robustecer una oposición eficaz y no sólo testimonial. Todo ello además del componente psicológico del ser humano consistente en el apetito de sentirse ganador o influyente y no derrotado e insignificante una vez tras otra. En el gran teatro de la política (ARANGUREN escribió sobre ello palabras muy inteligentes), en la magna representación que es la política, el elector quiere sentirse protagonista y no mero figurante.

tor quiere sentirse ganador hasta donde le sea posible y con unas opciones lo consigue mejor que con otras sin traicionar demasiado su posición ideológica.

43 También le sucedería al PSOE en las elecciones de 2000, aunque en proporciones numéricas incomparables. 
2.c) El elector español es conservador de su voto. A despecho de las encuestas que se publican durante toda la legislatura y que se intensifican en vísperas electorales (en realidad, siempre estamos en vísperas de unas elecciones u otras), al final se comprueba que más de un $90 \%$ de electores tienden a repetir su voto. Las elecciones se deciden en un 6-8\%, que no es poco ciertamente, pero que tampoco da para todo.

Ese 6-8\% de electores de los que se puede esperar cierto cambio se sitúan preferentemente (pero no sólo) en el centro del espectro ideológico, tramo en el que se libra la principal batalla electoral, y los que, situándose a la izquierda del PSOE se plantean abandonar su alineación política «de siempre» para votar «útil» y hacer fija su nueva opción. A lo cual hay que añadir la actitud volátil de cierto electorado de izquierda, consistente en acudir o no acudir a las urnas, pero no en cambiar el signo de su sufragio.

(En el cuadro número 1 puede observarse la sobrerrepresentación de los dos principales partidos en todas las elecciones generales hasta 2004; en el cuadro número 2, esa misma relación en las elecciones de 2008 y en los números $\mathbf{3}$ y 4, la tendencia a la concentración del voto en ellos.)

2.d) En fin, por lo general, el electorado se ha dividido a partes iguales o casi iguales entre los dos grandes partidos de implantación nacional y, por consiguiente, los resultados han deparado sólo la mayoría relativa a uno de ellos. Así se pudo observar en las dos primeras elecciones y desde 1993 hasta nuestros días, salvo en la convocatoria de 2000. En 1982 el PSOE se benefició de la debacle de la derecha y obtuvo una abultada mayoría absoluta, de cuyas rentas siguió viviendo en las siguientes elecciones. Y en 2000 el PP alcanzó también mayoría absoluta no tanto por el cambio de orientación del electorado habitual del PSOE, sino por su acentuada abstención, que no se mantuvo en la convocatoria siguiente. Esta semiconstante de mayorías relativas es otro rasgo de nuestro sistema político y precisamente el que permite a los partidos nacionalistas tener un gran peso específico en la política nacional.

3. Debe de ser muy costoso arrebatarle votos al partido que los viene disfrutando, pero también, o acaso más, recuperar los que se van perdiendo elección tras elección. Lo que viene a significar que, en un horizonte temporal no muy dilatado, son peores las expectativas electorales de las fuerzas políticas que llevan quince años declinando (es el caso de Izquierda Unida) que de las que se asoman a la contienda con un proyecto renovador y moderado.

4. Una mejora de la proporcionalidad del sistema electoral sin reforma constitucional no puede deparar grandes expectativas ni a unos ni a otros, pero, a mi juicio, a unos menos que a otros. Sin embargo, las fuerzas políticas de menor implantación nacional pueden aspirar, si la proporcionalidad mejora algo, a 
jugar un papel importante, y aun decisivo, sobre todo en las legislaturas en las que no hay mayoría absoluta homogénea en el Congreso de los Diputados, las cuales, hasta la fecha, resultan ser nada menos que dos tercios del total. Sus escaños, entre cuatro y siete, pueden ejercer un papel determinante en la gobernación del Estado, liberando al partido con más escaños de la hipoteca nacionalista.

Este papel puede jugarlo mejor UPyD que IU, porque ésta no puede negociar con el PP, salvo que quiera reeditar la teoría de las dos orillas, que tan elocuentes resultados le dio en su momento. Cómo conseguir esa modesta mejora es el objeto de la siguiente reflexión y uno de los objetivos de este Seminario.

5. Finalmente, los dos partidos de mayor implantación nacional se hallan en diferente posición negociadora con las fuerzas políticas nacionalistas a la hora de concertar un pacto de legislatura o apoyos puntuales en la Cámara. Bien es verdad que tanto uno como otro han terminado pactando, como hemos reseñado en páginas anteriores, pero la deriva actual, muy antinacionalista, del Partido Popular se lo pone francamente más difícil, como se demuestra en algunas Comunidades Autónomas. Lo que viene a significar que, si finalmente se alcanza el acuerdo, seguramente será con el coste de una mayor contraprestación.

\section{PROPUESTAS DE REFORMA}

\subsection{La supuesta rigidez fáctica de las leyes electorales}

Como dijimos en un epígrafe precedente, dejamos a un lado las propuestas sobre el carácter cerrado y bloqueado de las candidaturas porque apenas afectan a nuestro objeto, al menos al que yo he querido sujetar mi ponencia.

Es sintomático que no se planteen reivindicaciones sobre el sistema electoral autonómico, sino sólo sobre el vigente para el Congreso de los Diputados. Más aún: el sistema existente para las elecciones al Senado no es contestado por su mayor o menos capacidad para reflejar la opinión del electorado español, sino por su escasa significación autonómica, como es lógico si se toma en serio que es una Cámara de la que se dice que representa los territorios de un Estado compuesto. Y, aunque algunas medidas electorales autonómicas (por ejemplo, en Murcia y en Canarias) han sido cuestionadas jurídicamente, el resultado ha sido infructuoso ${ }^{44}$.

\footnotetext{
${ }^{44}$ En realidad, la jurisprudencia electoral del Tribunal es tosca y no siempre correctamente fundamentada.
} 
De otro lado, hemos de convenir en si se quiere una reforma del sistema electoral que no se detenga ante el artículo 68 de la Constitución, o bien que opere solamente sobre la Ley Orgánica del Régimen Electoral General. Lo primero choca con obvias resistencias, no tanto jurídicas, que también, cuanto de consenso entre las principales fuerzas políticas. Pero lo segundo, además de encontrar asimismo dificultades de consenso, bien que menores, tiene un alcance mucho más corto y no podemos abrigar demasiadas esperanzas de que la mejora obtenida sea sustancial, puesto que los elementos esenciales del sistema, y muy concretamente la circunscripción electoral, se encuentran regulados precisamente en dicho precepto constitucional. La modificación de este elemento no ha entrado hasta ahora en la agenda política de nuestros principales dirigentes y tampoco se otea en el horizonte que pueda hacerlo en breve.

Todo lo cual abona la tradicional convicción acerca de la «inmodificabilidad» o rigidez fáctica de las leyes electorales, con la que en realidad quiere aludirse a la extraordinaria dificultad que presentan para su reforma. Ahora bien, para que esta "doctrina» sea correcta, hemos de añadirle dos matices: a) Se trata de una dificultad más política, que jurídica. b) Es así, sobre todo, si la reforma puede perjudicar al o a los beneficiarios del sistema, ya que las reformas contrarias se hacen a menudo, y el ejemplo vuelve a estar en Canarias.

El problema que nos preocupa más y que nos reúne hoy aquí es el de una eventual reforma del sistema electoral para el Congreso de los Diputados y a él van dirigidas las siguientes reflexiones.

\subsection{Reforma electoral sin reforma constitucional}

$\mathrm{Si}$, por los motivos indicados anteriormente, circunscribimos la reforma a la sola LOREG, los retoques sugeridos en la tribuna pública, bien por actores políticos, bien por expertos en la materia, son, entre otros:

a) aumentar el número de diputados de 350 a 400;

b) distribuir los nuevos cincuenta escaños entre las circunscripciones actuales o hacer con ellos una «bolsa» para distribuirlos entre los restos nacionales de las diversas candidaturas;

c) rebajar de dos escaños a uno la cuota fija provincial;

d) cambiar la fórmula de D'Hondt por la de resto mayor o por la de Santa Lagüe corregida para la asignación de escaños, y

e) concentrar los votos de los españoles residentes en el extranjero en un solo escrutinio y con reserva de un cierto número de escaños en vez de ser 
escrutados, como hasta ahora, en la circunscripción provincial en la que están censados.

\subsubsection{Sobre la constitucionalidad de las bolsas nacionales de escaños}

Si se hicieran los cinco cambios indicados, la reforma sería importante, aunque no determinante $y$, a medida en que la reforma prescinda de uno o varios de ellos, su alcance se irá haciendo más insignificante. Pero debemos despejar una incógnita previa relativa a la constitucionalidad de esas dos reservas de escaños para distribuirlos nacional y no provincialmente.

La duda proviene de los términos categóricos con los que se expresa el artículo 68.2 de la Constitución, tanto para referirse a la circunscripción electoral, a las excepciones expresas de Ceuta y Melilla y, finalmente, a la distribución de la totalidad de los escaños de la forma muy concreta con que la prescribe:

«La circunscripción electoral es la provincia. Las poblaciones de Ceuta y Melilla estarán representadas cada una de de ellas por un Diputado. La ley distribuirá el número total de Diputados asignando una representación mínima inicial a cada circunscripción y distribuyendo los demás en proporción a la población».

Mi opinión sobre el particular es doble. Personalmente creo que las medidas propuestas son inconstitucionales por al argumento antes mentado. Pero también estoy persuadido de que, primero, nadie las impugnaría por inconstitucionales, y, segundo, que, si así se hiciere, la respuesta del Tribunal Constitucional sería desestimatoria. Le basta para ello la argucia de no calificar dichas reservas de escaños como circunscripciones, sino, aunque el texto constitucional impide que haya escaños sobrantes, como bolsas de escaños sobrantes por necesidades de ajuste y para mejor cumplir el mandato constitucional de que el sistema sea proporcional.

Sin embargo, para no duplicar inconstitucionalidades, sería preciso que en ese reparto nacional participaran todos los partidos contendientes, puesto que tan sin escaño queda la fuerza política que no obtiene ninguno como la que, habiendo alcanzado uno o varios, se queda sin el siguiente porque lo gana otra candidatura por escasa diferencia en sus respectivos cocientes. 
12.2.2. Cambiar la fórmula de distribución de los escaños ${ }^{45}$

a) Fórmula del resto mayor

La fórmula de resto mayor facilita la obtención del primer escaño por debajo del propio cociente electoral y también por debajo del primer cociente de la fórmula de D'Hondt, puesto que, como su propio nombre indica, basta con tener un resto mayor que las otras candidaturas después de que todos hayan obtenido los escaños correspondientes a sus cocientes. Consiguientemente, su adopción daría alguna oportunidad a los partidos pequeños, especialmente en las circunscripciones mayores, siendo sus posibilidades prácticamente nulas en las menores, que son casi todas las de nuestro sistema electoral.

Aun así, operando con los datos actuales, las fuerzas políticas ahora perjudicadas (IU y UPyD) sólo conseguirían un par de escaños más cada una (uno en Madrid y otro en Barcelona). Bien poca cosa, como se ve, pero no despreciable.

b) Santa Lagüe corregida

La fórmula de Santa Lagüe opera con divisores muy altos. La versión más conocida y usual en países escandinavos lo hace con los números 1'4, 3, 5, 7, etc., lo que dificulta la obtención del primer cociente "competitivo" para entrar en el reparto por cuanto ha de vencer el obstáculo formidable del divisor 1'4. Pero también dificulta los sucesivos avances de las candidaturas en el reparto, puesto que la progresión de los números divisores es muy fuerte.

En efecto, volviendo de nuevo a los números, el paso del primer al segundo divisor significa un incremento del $114 \%$. Lo que quiere decir que para que una candidatura logre el segundo escaño antes de que la siguiente consiga el primero ha de superarla en más del doble de votos. El paso del segundo escaño al tercero representa un incremento del 66\%; del tercero al cuarto, uno del $40 \%$, etc.

En una palabra, esta fórmula, coeteris paribus, propende a favorecer en cierta medida a los partidos medianos.

La versión corregida y atenuada utiliza los números divisores $1,3,5$, 7, etc., lo que hace menos penoso alcanzar un primer buen cociente y permite la entrada de los partidos menores en el reparto de escaños en tanto sigue dificultando la obtención de nuevos escaños.

${ }^{45}$ Debo hacer una remisión general al excelente libro de C. Vidal Prado El sistema electoral español. Una propuesta de reforma, Granada, 1995, en el que hace unas certeras simulaciones de distribución de escaños cambiando la fórmula electoral, la cuota fija de escaños por circunscripción y el número total de diputados. 
En comparación con la exigencia del primer divisor, el segundo representa el $300 \%$ (con un incremento del 200\%), es decir, requiere que un partido más que triplique a otro en votos para sumar el segundo escaño antes de que éste consiga el primero. En el ejemplo propuesto a continuación se observa cómo con casi el triple de votos que C, A no logra el segundo escaño si la circunscripción es muy pequeña.

Tiene, por tanto, todo su sentido que sea esta última versión la utilizada por Izquierda Unida en su reciente propuesta de reforma del sistema electoral.

De nuevo los números nos eximen de grandes párrafos explicativos. Sea una circunscripción de tres escaños, como tantas en España, y unos resultados, en votos, de 20.000 para la candidatura A, 13.000 para la B y 7.000 para la C. El reparto final sería de un escaño para cada candidatura, lo cual es muy poco proporcional. En efecto:

$$
\begin{aligned}
& \frac{1}{2} \frac{3}{20.000}-6.666 \\
& \text { A: } \mathbf{1 3 . 0 0 0}-4.333 \\
& \text { C: } 7.000-2.333
\end{aligned}
$$

Mientras que con la fórmula de Santa Lagüe tradicional el reparto quedaría así: A:-2; B-1; C-0.

Si seguimos operando con el mismo ejemplo, podemos observar que la proporcionalidad no comienza a ser equilibrada hasta el octavo o noveno escaño, aunque siempre con la propensión dicha de mejorar algo al segundo partido. Ahora bien, con tal número de escaños también comienza a ser proporcionado el reparto con la fórmula de D'Hondt. La ventaja de la fórmula de Santa Lagüe corregida para el tercer partido es que casi tiene asegurado un escaño, sobre todo si la circunscripción es pequeña; pero esto es precisamente lo que ocurre en España. Quien propone, sabe lo que hace.

\section{c) Fórmula de d'Hondt corregida}

Nadie lo ha sugerido hasta ahora, pero, puestos a jugar con los números y a beneficiar al tercer o cuarto partido, no hay inconveniente jurídico alguno en adoptar la fórmula vigente actualmente con la corrección de los divisores, pudiendo quedar éstos en 0 ' 5,1 '2, 2, 3, etc., con lo que se adoptaría una progresión entre los tres primeros algo más suave que con la propuesta examinada anteriormente y que no beneficia a ninguna candidatura e manera manifiesta en el reparto de los primeros escaños. 
Los pasos del segundo al tercer divisor y del tercero al cuarto significan una exigencia un $140 \%$ y un $66 \%$ mayor respectivamente. El salto del primero al segundo divisor es más alto que en Santa Lagüe no corregida; el siguiente es igual, y en lo sucesivo se va suavizando, Es decir, como se dificulta mucho un segundo buen cociente, el partido pequeño tiene una buena oportunidad de conseguir un escaño, pero normalmente no pasará de ahí.

Con los mismos votos del ejemplo visto, tendríamos: A-2; B-1; C-0; y con cuatro escaños a repartir, A-2; B-1; C-1

$$
\begin{array}{ccc}
0{ }^{\prime} 5 & 1 \text { '2 } & 2 \\
\text { A: } \mathbf{4 0 . 0 0 0}-\mathbf{1 6 . 6 6 6}-10.000 \\
\text { B: } \mathbf{2 6 . 0 0 0}-10.833-6.500 \\
\text { C: } 14.000-5.833-3.500
\end{array}
$$

La proporcionalidad comienza a mejorar a partir del sexto escaño (con 3-21) y el tercer partido asegura el primer escaño únicamente si hay cuatro en juego, todo lo cual es, desde luego, más ajustado que con la fórmula anterior.

Como puede apreciarse, la clave reside no tanto en si es alto o bajo el primer divisor, puesto que es igual para todos, sino en la progresión más o menos acentuada de la serie de divisores. Si lo es mucho, queda favorecida la obtención del primer escaño por parte del partido pequeño, y sucede lo contrario si es más suave.

Con todo, no se yo si la clase política española es muy dada a entretenerse con los números; más bien barrunto que no.

\subsubsection{Rebajar la cuota fija provincial}

En segundo término, rebajando la cuota fija provincial de dos escaños a uno se liberan 50 escaños, a repartir entre todas las provincias según su población. Esto mejoraría la representación en las grandes circunscripciones y dejaría prácticamente igual las medianas, pero restaría un escaño a las menores. Lo que significa que Soria quedaría con sólo un escaño, las provincias que ahora tienen tres pasarían a tener dos, y que las que tienen cuatro, cinco e incluso seis también sufrirían la rebaja de uno, con lo que acaso mejorara la proporcionalidad del sistema electoral tomado en su conjunto (para ello habría que hacer la correspondiente simulación; remito de nuevo al estudio, ya citado, de Carlos VIDAL, que trata estas cuestiones empíricamente), pero no gran cosa porque tiene que enjugar el empeoramiento en las circunscripciones que pierden un escaño.

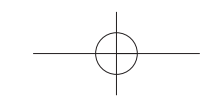




\subsubsection{Aumentar el número de escaños a 400}

Tomando como justificación que nuestra Cámara Baja es una de las que tienen una ratio población/diputados más baja de Europa, puede razonablemente aumentarse el número de éstos a 400. Pero, si se dejan intactos los demás elementos, no se ganaría demasiado, porque esos 50 escaños de más corresponderían en su mayor parte a las grandes circunscripciones, cuya proporcionalidad actual ya es bastante aceptable. De todos modos, el sistema sería algo más justo para IU y UPyD, que podrían obtener un escaño en algunas circunscripciones en las que ahora se quedan en puertas, pero seguirían sin alcanzar a algunos partidos nacionalistas con menos votos y más escaños, que son con los que se suelen comparar.

\subsubsection{Modificación combinada de dos o más elementos del sistema}

a) Aumento de escaños a 400 y rebaja de la cuota fija provincial

Más entidad tiene la combinación de los dos elementos anteriores pero, aun así, seguiría arrojando una proporcionalidad escasa por las razones expuestas anteriormente: muchas circunscripciones seguirían eligiendo menos diputados que con el sistema actual porque los cien escaños liberados serían asumidos por las provincias más pobladas y actualmente subrepresentadas. En el cuadro número 4, se observa que IU duplica sus escaños mientras que UPyD queda como ahora; a cambio, CiU incrementa los suyos en cuatro y ERC y CC en uno; lo que, dicho en román paladino, para ese melón...

A fin de que la reforma sea más efectiva en términos de reconocer a partidos de menor implantación nacional un peso en la política nacional aproximado a los sufragios que obtienen, habría que combinar tres elementos, los dos mencionados y la última variante que ha sugerido IU en su propuesta final, pero mejorándola: en vez de hacer una bolsa de 50 escaños para distribuirla en proporción a los votos obtenidos por las respectivas candidaturas en toda España, hacerla de los 100 escaños que liberamos con las dos operaciones anteriores.

Para que esta propuesta sea constitucional deben participar en este nuevo reparto todas las candidaturas y no sólo las que no consiguieron escaños en alguna circunscripción. Por más que otra vez los mayores beneficiarios serían PSOE y PP, cien escaños dan margen suficiente para que los partidos de menor implantación nacional arañen algunos que sumar a los que ahora consiguen, en el bien entendido de que no perderían ninguno de los que ahora tienen. 
Y todavía se puede mejorar la proporcionalidad si la reforma alcanza a cuatro elementos: los ya comentados y la adopción de la fórmula de resto mayor.

Añadiré para finalizar que me parece preferible operar con fórmulas conocidas antes que andar corrigiéndolas de modo muy alambicado. Las variaciones indicadas son sencillas y comprensibles. Ir más allá no parece conveniente y puede sembrar dudas acerca de su posible inclinación a favor de unos u otros. Tengamos en cuenta que una de las cualidades que más se valoran de los sistemas electorales por parte e la ciudadanía es su sencillez. De ahí el éxito de los sistemas de mayoría pese a su olímpico olvido de las matemáticas.

\subsection{Reforma electoral con reforma constitucional}

Quienes ahora instan la reforma del sistema electoral para el Congreso de los Diputados no osan incluir en su propuesta la modificación de la circunscripción. Éste es un elemento del sistema que se encuentra rigidificado, cuasipetrificado en el artículo 68 de la Constitución y cuenta además con la complacencia de los dos partidos de mayor implantación nacional, que son sus beneficiarios netos.

Por eso, si se quiere obtener una buena proporcionalidad, lo primero que habría que hacer es modificar el artículo 68 de la Constitución y sustituir la provincia por la Comunidad Autónoma como circunscripción electoral. Y, aun así, hay que anotar algunos datos empíricos:

1. Calculando sobre los 350 escaños actuales, seguiría habiendo circunscripciones pequeñas y medianas:

a) De las siete Comunidades Autónomas uniprovinciales, La Rioja, Cantabria y Navarra tendrían, por población, 2, 3 y 3 escaños respectivamente, y sólo pasarían a ser medianas si se estableciera una cuota fija autonómica de cuatro escaños.

b) En tal caso, otras dos circunscripciones uniprovinciales (Baleares y Asturias) estarían en el límite superior de las medianas, Murcia pasaría a ser circunscripción grande y Madrid, lógicamente, continuaría siéndolo.

2. Las demás Comunidades Autónomas, tanto las biprovinciales (Extremadura y Canarias) como el resto, serían circunscripciones grandes.

3. Ceuta y Melilla continuarían como hasta ahora.

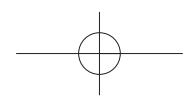


Con esta reforma se alcanzaría una proporcionalidad muy ajustada. Seguiría habiendo desigualdad de voto ${ }^{46}$, pero seguramente menos que en la actualidad; al fin y al cabo, más hay en las elecciones al Senado. Ahora bien, tanto la proporcionalidad como la igualdad de voto mejorarían aún más con 400 escaños $^{47}$. En tal caso, resultaría casi indiferente que la fórmula de escrutinio fuera la de D'Hondt o la del resto mayor.

\section{LA REPRESENTACIÓN COMO REFLEJO Y COMO INTEGRACIÓN EN EL SISTEMA ${ }^{48}$}

Los Parlamentos tienen las muy importantes funciones que tienen porque están revestidos de legitimidad democrática inmediata al ser elegidos sus miembros por el cuerpo electoral. La representación, la representatividad, es, pues, un prerrequisito de su legítimo funcionamiento. Pero el sistema electoral no es sino un subsistema del sistema político en su conjunto y, si bien es sumamente importante, no determina de manera absoluta a éste ni califica por sí solo su representatividad. Un correcto sistema electoral es condición necesaria para todo ello, pero no suficiente.

A pocos británicos, al menos a pocos ingleses, se les ocurriría calificar la Cámara de los Comunes como no representativa o deficientemente representativa, pese a que su sistema electoral funciona sobre una (fáctica) pérdida masiva de sufragios. Acaso pueda decirse lo mismo de los franceses respecto de la Asamblea Nacional, aunque en los últimos tiempos se hayan quedado sin escaño candidaturas que alcanzaron hasta un $20 \%$ de los sufragios.

¿Qué duda cabe de que, en comparación con dichos Parlamentos, nuestro Congreso de los Diputados es matemáticamente mucho más representativo? Y, sin embargo, respecto de él sí surgen quejas. La clave reside, según creo, en el mejor funcionamiento de esas otras dos Cámaras, dicho sea con algunas reservas respecto de la Asamblea Nacional francesa; en que la ciudadanía siente que el Parlamento asume sus demandas reales y les da respuesta, que ejerce sin graves altibajos sus funciones legislativa, presupuestaria y, sobre todo, controladora

${ }^{46}$ La mayor se produciría ahora entre La Rioja y Madrid.

47 El Congreso de los Diputados es una de las Cámaras con una ratio población/diputados más reducida de Europa, aunque mayor que la de la Cámara de Representantes estadounidense.

${ }^{48}$ Cfr mi trabajo "Representación y sistemas electorales», en GARrorena, A. (ed.): El Parlamento y sus transformaciones actuales, Madrid, 1990; de igual factura, «Ley Electoral y representación», en RAMírEZ (ed.): El Parlamento a debate, Fundación «Lucas Mallada» y Editorial Trotta, Madrid, 1997, págs. 15-27. 
del Ejecutivo; en una palabra, la clave reside en el buen funcionamiento de la democracia representativa. Y esto es mucho más decisivo que el ajuste centesimal de la relación votos/escaños.

Estamos, pues, ante dos dimensiones de la representación. Una estrictamente racional y objetiva: el reflejo a escala de la voluntad general. Otra subjetiva: sentirse el ciudadano representado por el Parlamento en su conjunto y no, o no sólo, por «su» diputado, lo que lleva a aquél a sentirse identificado con el sistema en el que vive, integrado en él, y no se le ocurre poner en entredicho su legitimidad ${ }^{49}$. Yo, que soy racionalista por formación y por talante, entiendo que es políticamente más importante esta segunda dimensión de la representación. Intentar reducir la política a matemáticas tiene muy corto recorrido.

Es verdad que en los países referidos hay algunas protestas. En Inglaterra, lo hace el Partido Liberal Socialdemócrata, que con bastantes votos apenas alcanza escaños; pero su protesta es tomada como un elemento más del paisaje político: se cuenta con ella, se sabe que hay que oírla de vez en cuando y nada más. En Francia protesta Le Pen; pero, al igual que en el caso anterior, dichas lamentaciones apenas conmueven a los poderes públicos: dura lex, sed lex.

Sin embargo, en España se protesta. El asunto tiene mucho que ver con la segunda significación de la representación. Aunque la representatividad del Congreso y, por tanto, su legitimidad democrática, no ha sido negada por nadie solvente (ha sido negada por algunos, sí, pero por nadie solvente), resulta manifiesto que hay un cierto desentendimiento, una lejanía de los ciudadanos respecto de la política porque no se sienten representados en el Congreso. Ahí radica la cuestión, según creo: no en que la Cámara no refleje aritméticamente la opinión del electorado, sino en que éste no se siente identificado con dicha Cámara, no se reconoce en ese espejo, no la aprecia como emanación suya y, como consecuencia, tampoco se siente integrado en el sistema político del cual dicha Cámara es o debería ser la pieza central.

${ }^{49}$ Nada de esto tiene que ver con el principio de identidad schmittiano; nada con la aspiración política de prescindir, por innecesarios, de los procedimientos democráticos formales de la democracia representativa; nada, en fin, con la alienación nacional en ningún conductor, ni individual, ni colectivo, ni colegiado, que sea venerado como la encarnación del espíritu del pueblo. La identidad, así entendida, valga la paradoja, es, lo ha sido históricamente, la mayor de las alienaciones. La identificación de la que hablo no es alternativa a la representación, sino que lo es de la ciudadanía con los órganos representativos en cuanto tales; es decir, en cuanto temporales, en cuanto electivos y en cuanto sometidos a la soberanía del elector. Esta identificación del ciudadano con las instituciones representativas se basa también, en buena parte en una cuidada y consolidada cultura cívica. 
Dicho sentimiento de identificación con la Cámara y de integración en el sistema político es algo subjetivo, emocional si se quiere, acaso insusceptible de ser jurídicamente racionalizado, pero no es irracional, y, desde luego, es políticamente determinante. Esto es lo que siente el ciudadano británico común con la Cámara Baja y esto es precisamente lo que está fallando en el Congreso de los Diputados en España, al menos desde hace veinte años.

¿Dónde está el punto de inflexión?; ¿en el sistema electoral? Puede que sí, pero no del todo. Pensemos en el Senado. ¿Acaso alguien piensa que su problema, su desdibujamiento en el funcionamiento del aparato estatal y en la opinión pública es debido al sistema de mayoría con el que son elegidos sus miembros? El problema del Senado es otro, como se sabe. Reside en su configuración constitucional, que no logró hacer de él una Cámara de representación territorial ni lo dotó de protagonismo institucional suficiente, de suerte que ordinariamente actúa no como segunda Cámara, sino como mera Cámara secundaria.

Si se me permite la digresión, esta disyunción del concepto de representación también se percibe en la Corona. El Rey representa al Estado español ope Constitucionis, puesto que así lo dispone el artículo 56 de nuestra norma suprema. De ahí que se le rindan dentro y fuera de España los honores debidos a ésta como Estado soberano y miembro de las Naciones Unidas. También, por ende, nos representa a los españoles por cuanto somos miembros de ese mismo Estado y conformamos uno de sus presupuestos básicos: la población (en sentido sociológico) o el pueblo (en sentido jurídico), que es soporte básico de la estructura estatal $^{50}$. Desde el punto de vista jurídico, el asunto está zanjado, lo mismo que lo está la representación del hijo por el padre ope legis, dado que así lo establece el Código Civil. Qué duda cabe, sin embargo, que, desde el punto de vista político, esa representación será tanto más efectiva si el funcionamiento de la Corona y la trayectoria del Rey como Jefe de Estado logra despertar en la ciudadanía un sentimiento de adhesión a la persona del Rey, el sentimiento (subjetivo y emocional, sí, pero no irracional ni irrazonable) de verse representada por el titular de la Corona

Viniendo de nuevo a nuestro problema, concluiremos que el arraigo de las instituciones representativas reside más, mucho más en el diseño de sus funciones y de su funcionamiento. Consiguientemente, el surgimiento de ese senti-

${ }^{50}$ Prefiero hablar de soporte básico o de presupuesto y no de elemento porque el Estado es una estructura formal y sus elementos deben ser formales, a saber, el derecho y el poder. La población y el territorio más que elementos son presupuestos materiales del Estado. Cfr. mis obra Estado de Derecho y democracia de partidos, ob. cit., págs. 31 ss. 
miento de integración, siempre que el sistema electoral cumpla unos mínimos democráticos, como sucede en nuestro país (y si son más que mínimos, mejor), depende acaso más de unos buenos reglamentos parlamentarios y una buena legislación sobre partidos:

- Un estatuto jurídico completo de la Oposición.

- Una actuación cohesionada de ésta (en España, muy principalmente, del segundo partido con implantación nacional ${ }^{51}$ y dirigida a crear una razonable alternativa de Gobierno y no a la simple crispación del ambiente político.

- Unos reglamentos parlamentarios que den facilidades a los grupos menores para ejercer su función de control del Gobierno; que ofrezcan mayores oportunidades a la Oposición para la confección del orden del día; que dispongan una mayor presencia del Gobierno en las Cámaras; que impidan la utilización torticera del Senado en el proceso legislativo, como lamentablemente se hizo al final de la VII legislatura; que regulen mejor las comisiones de investigación, que ahora sólo sirven para el navajeo político, y un dilatado etcétera.

- Además de, claro está, una legislación de partidos que propicie su mayor democracia interna y se tome en serio la financiación de los mismos y su control.

- Y acaso la apertura y el desbloqueo de las candidaturas, o una sola de estas dos exigencias, para así favorecer el protagonismo del elector y su implicación en la composición final de la Cámara, si bien estos dos rasgos pueden presentar tantos inconvenientes como ventajas en orden a la disciplina interna de los partidos que, al fin y al cabo, son unidades de acción política y el resquebrajamiento de esa unidad los suele dejar heridos de muerte.

Todo ello trascenderá seguramente hacia la ciudadanía con una imagen de transparencia que vendrá a facilitar la identificación de ésta con el sistema político en su conjunto.

${ }^{51}$ Recientemente, F. VALLESPÍN ha llamado la atención sobre ello en las páginas de la prensa. En la democracia española — dice— se ha venido cumpliendo a rajatabla dos «leyes de hierro»: una es el declive electoral de los partidos que trasladan una imagen de desunión; otra, que sin una Oposición sólida, aumentan los desvaríos del Gobierno y disminuye su rendimiento (El País, 132-2009).

(C) UNED. Revista de Derecho Político

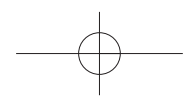




\section{PROPUESTA FINAL}

¿Quiere decir lo que antecede que hemos de abandonar toda pretensión de mejorar la representación objetiva o que son inconciliables ésta y la representación subjetiva? En absoluto. No esgrimimos la teoría esbozada sobre las dos dimensiones de la representación para evitar encararnos con el problema que nos ocupa porque también el sistema electoral tiene mucho que ver con todo esto. Lo único que hemos querido significar es que el ajuste votos/escaños, por sí solo, no mejora gran cosa el funcionamiento de la democracia y que, por ende, hay que trabajar en los dos frentes, o en tantos cuantos que sean pertinentes, y no fiarlo todo a las matemáticas.

Pero tampoco las matemáticas son incompatibles con los sentimientos, en nuestro caso el sentimiento de integración en el sistema político. Antes resumíamos las virtudes de los dos grandes sistemas electorales haciendo residir en el proporcional la justicia electoral y el aprovechamiento de todos los sufragios, y en el de mayoría, entre otras, en la vinculación estrecha entre el diputado y sus electores. ¿Por qué no buscar dichas virtudes en un solo sistema?

Pero ya dije que en esto no hay prestidigitación ni milagros. Esa fórmula existe, existe en Alemania desde hace muchos años y da un rendimiento magnífico. No hay que inventar nada: está inventado.

La idea se le ocurrió al socialista austriaco Frederic ADLER y después fue sistematizada y divulgada por los franceses A. BRACKE y WEIL RAYNAR. De ahí que se la conozca en tratados y monografías como «sistema ABWR». Consiste en combinar el sistema proporcional con el voto personal en distritos creados al efecto. De esta manera, hay a un tiempo justicia electoral y vinculación entre diputado y elector.

En Alemania le han dado más de una versión, pero la idea sigue siendo esencialmente la misma. El alemán no es propiamente un sistema electoral mixto, como suele decirse, sino un sistema proporcional que opera con doble papeleta. Con una se vota al partido; con la otra se vota al candidato preferido en el distrito, que puede ser de una formación política diferente. Aunque la circunscripción es el Land, el territorio nacional se divide en un número de distritos electorales igual al 50\% de los diputados que integran el Bundestag, en los cuales resulta más votado un solo candidato.

Prescindiendo de ciertos pormenores, la forma de distribución de escaños ha experimentado algunos cambios con el tiempo, pero en esencia consiste en asignar a las diferentes candidaturas los escaños que le corresponden proporcionalmente, pero, a la hora de decidir nominalmente quiénes se sientan en la Cámara, los candidatos que han ganado en su distrito tienen asegurado su escaño 
con preferencia sobre sus compañeros de candidatura. El resto de los escaños corresponde a los candidatos incluidos en las listas y según el orden establecido en las mismas.

El sistema, como digo, funciona correctamente, salvo, para mi gusto, el muy elevado umbral de representación, o barrera electoral, que se ha establecido en el 5\% de los sufragios emitidos en todo el territorio nacional, cifra que me parece extremadamente injusta, aunque en España ha habido políticos que la han sugerido

En España, las leyes electorales autonómicas habrían podido ser la ocasión para introducir este modelo. Pero el mimetismo y la inercia prevalecieron sobre la decisión y la audacia. Lo mismo cabe decir de las elecciones municipales, y con mayor razón, puesto que en ellas tiene tanta significación o más la personalidad de los candidatos a las Alcaldías que su adscripción partidista. A la vista de los resultados se podría pensar en llevarlo a las elecciones generales.

Me temo que para algunos eso sería esperar demasiado y preferirían empezar por arriba, como se hizo hace 32 años. No seré yo quien lo desaconseje. Y estimo, por lo demás, que esta reforma puede hacerse sin modificación del artículo 68 constitucional.

En efecto, tanto si se dispone un voto nominal en cada circunscripción como si se opta por el voto a dos o más, no se percibe contradicción alguna con la norma fundamental. A mi juicio ${ }^{52}$, es esta última la fórmula apropiada para la modificación del sistema que se postula. Un solo voto nominal significa solo la séptima parte de la Cámara, frente al 50\% del modelo alemán. Sería más idóneo ampliar progresivamente el número de estos votos/escaños según la dimensión de la circunscripción:

- un voto nominal en las circunscripciones de dos a cinco escaños:

- dos, en las dotadas con 6-9 escaños.

- tres en las que superen esta cantidad, salvo en Madrid y Barcelona, en las que se podrían designar cuatro o cinco diputados por este procedimiento.

El sistema sigue siendo proporcional, ningún partido obtiene más escaños que los que les corresponderían conforme a la fórmula de escrutinio establecida y la circunscripción sigue siendo la provincia. Nada hay que roce siquiera el texto constitucional. Incluso cabe la división del territorio nacional en 200 distritos uninominales a los meros efectos de identificar el candidato ganador para ase-

${ }^{52} \mathrm{Me}$ he referido a esta posible introducción del modelo alemán en nuestro Ordenamiento hace casi veinte años en el trabajo «Representación y sistemas electorales», ob. cit., págs. 73-74. 
gurarle su escaño independientemente del lugar que ocupe en la candidatura de su partido, siempre que la circunscripción siga siendo la provincia; es decir: sigue siendo la provincia la entidad territorial a la que se le asignan los correspondientes escaños fijos y por población y en la que se distribuyen éstos entre las diferentes candidaturas por el sistema proporcional.

\section{UN EPÍLOGO DESDE LA PERPLEJIDAD}

Como era de esperar, no todo está dicho con lo expuesto hasta aquí. Este epílogo no puede ocultar el desasosiego de quien lo escribe, el cual se encuentra paralizado ante una perspectiva que, como todo lo que atañe a la vida humana, tiene diversas facetas, dos al menos.

Hoy, en los sistemas políticos como el nuestro, el Parlamento y el Gobierno están unidos en una suerte común, están ligados por una relación de confianza que el primero otorga al segundo y se la mantiene para que pueda gobernar, vale decir para que pueda dirigir la política nacional. Por eso, a nadie puede sorprender que las elecciones legislativas sean consideradas por el común de la ciudadanía no tanto ni principalmente como un modo de selección de legisladores cuanto de un equipo de gobierno.

Sin embargo, no todo está dicho con lo expuesto hasta aquí. Aunque las matemáticas e incluso la experiencia de algún país pueda abogar por una de las reformas que hemos sometido a consideración, está por ver si ésta o las otras reformas posibles redundarían en una mejora de la gobernabilidad del Estado, es decir, en la más fácil formación de los Gobiernos, evitando vacíos prolongados, y en su mayor consistencia. Porque no debemos olvidar que los partidos que más perderían con esta o estas reformas serían los dos grandes beneficiados hasta ahora, PSOE y PP, es decir los dos únicos que pueden formar Gobierno, extremo éste sumamente importante en una democracia parlamentaria y que, por tanto, no debe ser excluido del análisis, aunque sólo sea en su reflexión postrera.

Por lo demás, ¿̨de verdad hay que creer que nuestro peculiar y denostado bipartidismo es la fuente de todos los males patrios, en tanto que el multipartidismo lo sería de todos sus bienes? En pocos ámbitos como en éste es necesario reflexionar seriamente antes de pasar a la acción.

Pero todavía hemos de añadir algo para que sea cierta la perplejidad anunciada. Lo que comenzó siendo un sistema de partidos pluralista atenuado, con dos partidos en la derecha, tres en la izquierda y varias formaciones nacionalistas, amén de algunas regionalistas de menos entidad, sistema que fue capaz de con- 
sensuar una salida de la Dictadura, unos Pactos de la Moncloa, una Constitución y una superación más o menos airosa de varios intentos involucionistas, tiene hoy a la vista su desembocadura en un bipartidismo irreconciliable, casi cainita, que, para poder gobernar el Estado, tiene que apoyarse en quienes no creen en el Estado, quiero decir en este Estado. Después de treinta años, el sistema de partidos y el sistema político en general está llegando adonde querían evitar quienes lo diseñaron.

Tres semanas después del Seminario del que trae causa este número de la Revista J. PÉREZ ROYO publicó en El País un artículo ${ }^{53}$ de argumentación convergente con la de esta ponencia, del cual interesa destacar un par de consideraciones:

a) Desde 1993 se mantiene un empate técnico entre los dos grandes partidos de implantación nacional, PP y PSOE, pese a que ha habido acontecimientos importantes que podían haber tenido reflejo en el voto ciudadano, tales como la sustitución de los dos líderes principales, Felipe González y José María Aznar, el acceso al Gobierno catalán de una formación tripartita que ha desbancado la larga hegemonía de Convergència i Unió, el atentado del 11-M, las reformas de media docena de Estatutos de Autonomía en un sentido de claro incremento del autogobierno, las propuestas autodeterministas del lehendakari señor Ibarretxe y sus correspondientes rechazos, etc.

b) $\mathrm{Ni}$ el extraordinario crecimiento económico del periodo 1993-2007 ni la crisis actual ha tenido repercusión en el voto.

El Pfr. PÉREZ ROYO extrae de tales datos ciertos la conclusión de que dicho permanente empate parece llevar al sistema político a una cierta parálisis, por lo que puede decirse que el sistema no camina en la buena dirección. A mi juicio, tal afirmación es matizable, quizás a peor: no creo que haya parálisis en dosis preocupante, pero si un deslizamiento en dirección indeseable: el frentismo.

Hágase la reforma electoral o no, la que no debe demorarse es la señalada en un epígrafe precedente acerca de los reglamentos parlamentarios, la legislación

${ }^{53}$ PÉREZ ROYO, J.: «Voto atrincherado», El País, 8-XI-2008.

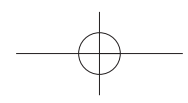


sobre los partidos, etcétera. Más allá de esa modesta indicación y de mi opinión acerca de la compatibilidad de la fórmula alemana con nuestra norma fundamental, no sé si esto tiene arreglo. Y lo siento.

Bayona, octubre, 2008 


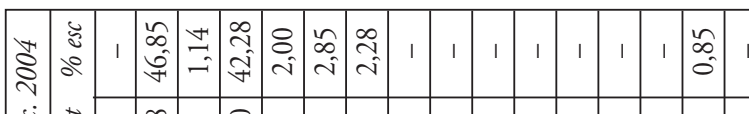

茫

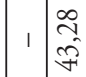

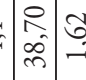

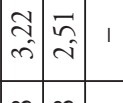

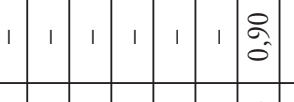

\begin{tabular}{l|l|l|l|}
\hline & & $\infty$ & $\hat{n}$ \\
$\tilde{0}$ & $\hat{2}$ & 0 \\
0
\end{tabular}

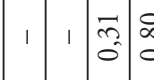

ஓ

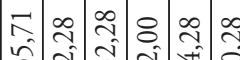

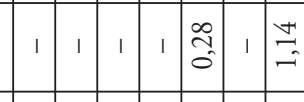

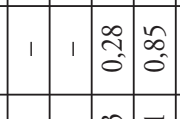

$\hat{\imath}$

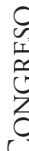

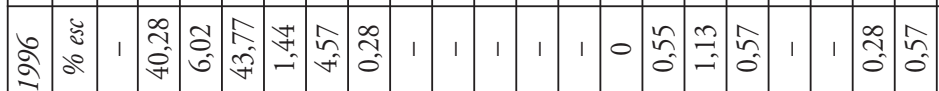

జు้

安

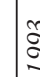

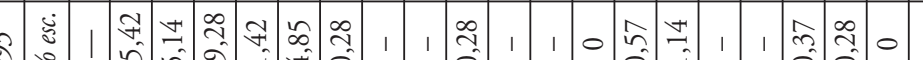

ज्ञ

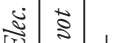

की जि के

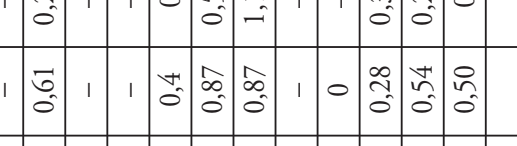

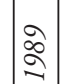

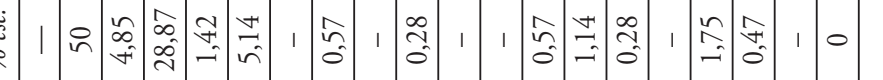

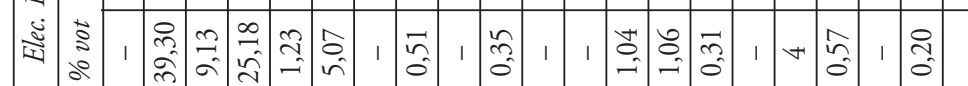

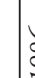

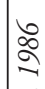

खँ

¿.

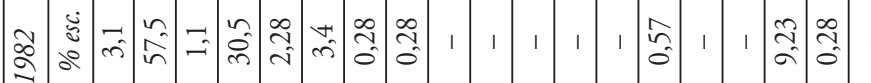

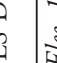

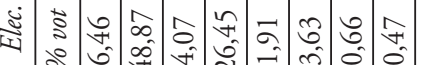

2

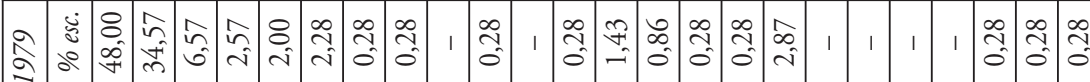

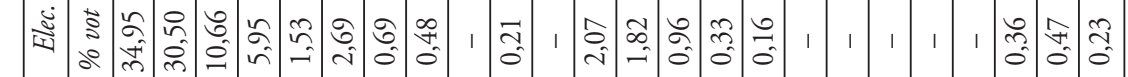

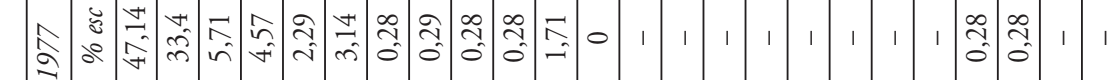

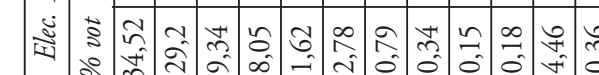

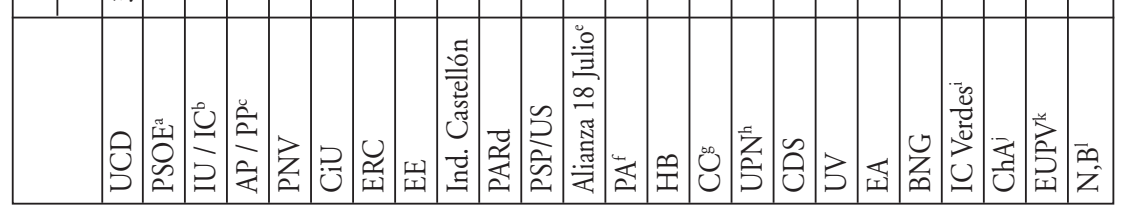

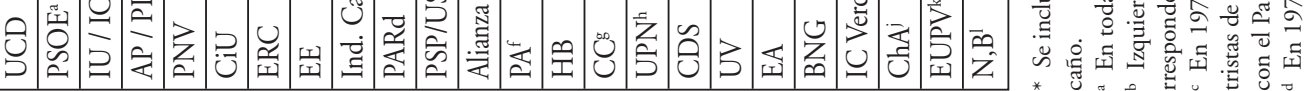

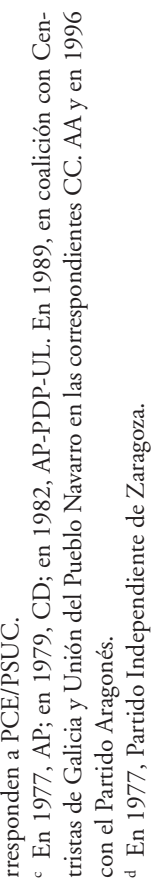

N. ${ }^{\circ}$ 74, enero-abril 2009, págs. 51-111

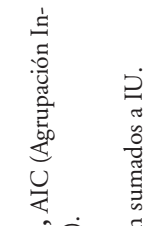

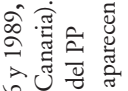

$\stackrel{0}{\circ}: \stackrel{0}{\circ}:$

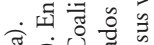

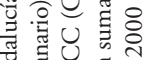

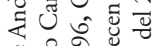

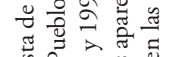

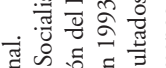

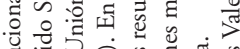

z

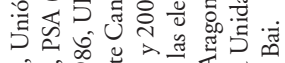

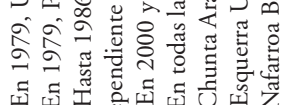

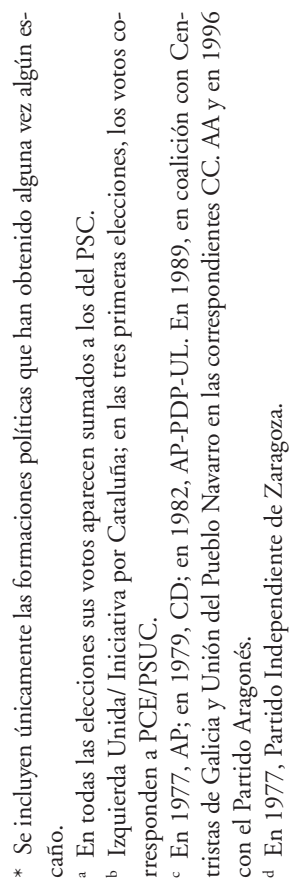

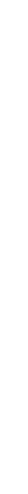


ANTONIO TORRES DEL MORAL

CuAdro N. ${ }^{\circ}$ 2. Distribución Oficial en las ElECCiOnes de 2008 y Simulación CON 400 ESCAÑOS Y 1 ESCAÑO FIJO POR PROVINCIA

\begin{tabular}{|l|c|c|c|c|c|}
\hline \multirow{2}{*}{} & \multirow{2}{*}{ Votos } & \multicolumn{2}{|c|}{ Distribución oficial } & \multicolumn{2}{c|}{$\begin{array}{c}\text { Simulac. } 400 \text { esc. } \\
\text { y } 1 \text { fijo por prov. }\end{array}$} \\
\cline { 3 - 6 } & & Escaños & $\%$ & Escaños & $\%$ \\
\hline PSOE + PSC & $10.144 .750^{* *}$ & 169 & 48,28 & 192 & 48 \\
\hline PP + UPN & $9.731 .846^{* * *}$ & 154 & 44 & 173 & 43,25 \\
\hline CiU & 779.425 & 10 & 2,85 & 14 & 3,5 \\
\hline EAJ-PNV & 306.128 & 6 & 1,71 & 6 & 1,5 \\
\hline ERC & 291.532 & 3 & 0,85 & 4 & 1 \\
\hline IU & 969.871 & 2 & 0,57 & 4 & 1 \\
\hline BNG & 212.543 & 2 & 0,57 & 2 & 0,5 \\
\hline CC-PNC & 174.629 & 2 & 0,57 & 3 & 0,75 \\
\hline NA-BAI & 62.398 & 1 & 0,28 & 1 & 0,25 \\
\hline
\end{tabular}

* Fuente: Montero, J. R.: Conferencia en los Cursos de Verano de la Universidad Complutense, El Escorial, 2008.

** Se incluyen los votos del PSC-PSOE.

*** Se incluyen los votos de UPN.

Cuadro n. ${ }^{\circ}$ 3. Porcentaje de Votos y escaños obTenidos POr los dos Partidos MAYORES.

\begin{tabular}{|l|l|l|l|l|l|l|l|l|c|c|}
\hline & 1977 & 1979 & 1982 & 1986 & 1989 & 1993 & 1996 & 2000 & 2004 & 2008 \\
\hline Votos & 64 & 65 & 75 & 70 & 64,5 & 73 & 76 & 80 & 82 & 85,9 \\
\hline Escaños & 70,5 & 72,5 & 88 & 72,5 & 79 & 84,5 & 84 & 88 & 89 & 92,3 \\
\hline
\end{tabular}

Se observa una tendencia al alza hasta 1982, que decae después por el desgaste del PSOE y la clausura de AP/PP en el denominado "techo de Fraga», y sube finalmente de manera ininterrumpida durante cinco elecciones, desde 1993. La deriva es homogénea en ambas secuencias, con la salvedad de las elecciones de 1996, en las que el gap decrece a ocho puntos, para mantenerse desde entonces porque ya no hay apenas margen matemático de crecimiento. (Naturalmente, se ha sustituido UCD por AP-PDP-UL en 1982; y más adelante, AP por PP.) 
Cuadro n. ${ }^{\circ}$ 4. Primas y MinOraciones de escaños en VArias legislaturas, EXPRESADOS EN PUNTOS LINEALES Y PORCENTUALES

\begin{tabular}{|l|c|c|c|c|c|c|c|c|c|c|c|c|}
\hline & \multicolumn{2}{|c|}{1977} & \multicolumn{2}{c|}{1982} & \multicolumn{2}{c|}{1993} & \multicolumn{2}{c|}{1996} & \multicolumn{2}{|c|}{2000} & \multicolumn{2}{|c|}{2008} \\
\cline { 2 - 14 } & Pts. & $\%$ & Pts. & $\%$ & Pts. & $\%$ & Pts. & $\%$ & Pts. & $\%$ & Pts. & $\%$ \\
\hline UCD & $+12^{\prime} 6$ & $+36^{\prime} 5$ & $-3^{\prime} 3$ & $-53^{\prime} 2$ & & & & & & & & \\
\hline PSOE & $+4^{\prime} 2$ & $+14^{\prime} 2$ & $+8^{\prime} 6$ & $+24^{\prime} 6$ & $+6^{\prime} 6$ & $+17^{\prime} 1$ & $+2^{\prime} 3$ & $+6^{\prime} 0$ & $+1^{\prime} 5$ & $+4^{\prime} 5$ & $+4^{\prime} 1$ & $+9^{\prime} 4$ \\
\hline AP/PP & $-3^{\prime} 5$ & $-45^{\prime} 2$ & $+4^{\prime} 0$ & $+19^{\prime} 5$ & $+4^{\prime} 7$ & $+5^{\prime} 9$ & $+5^{\prime} 4$ & $+13^{\prime} 7$ & $+6^{\prime} 8$ & $+17^{\prime} 4$ & $+2^{\prime} 2$ & $+5^{\prime} 3$ \\
\hline PCE/IU & $-3^{\prime} 6$ & $-38^{\prime} 2$ & $-3^{\prime} 0$ & $-184^{\prime} 2$ & $-4^{\prime} 4$ & $-45^{\prime} 9$ & $-5^{\prime} 15$ & $-48^{\prime} 8$ & $-3^{\prime} 2$ & $-58^{\prime} 1$ & $-3^{\prime} 6$ & $-86^{\prime} 5$ \\
\hline CiU & $+0^{\prime} 4$ & $+12^{\prime} 9$ & $-0^{\prime} 3$ & $-8^{\prime} 8$ & $-0^{\prime} 1$ & $-1^{\prime} 8$ & - & $-0^{\prime} 9$ & $+0^{\prime} 1$ & $+2^{\prime} 4$ & $-0^{\prime} 5$ & $-15^{\prime} 9$ \\
\hline PNV & $+0^{\prime} 7$ & $+42^{\prime} 5$ & $+0^{\prime} 4$ & $+19^{\prime} 3$ & $+0^{\prime} 2$ & $+15^{\prime} 4$ & $+0^{\prime} 15$ & $-11^{\prime} 0$ & $+0^{\prime} 5$ & $+31^{\prime} 6$ & $+0^{\prime} 4$ & $+28^{\prime} 6$ \\
\hline ERC & $-0^{\prime} 5$ & $-62^{\prime} 6$ & $-0^{\prime} 4$ & $-57^{\prime} 6$ & $-0^{\prime} 5$ & $-65^{\prime} 0$ & $-0^{\prime} 4$ & $-58^{\prime} 2$ & $-0^{\prime} 5$ & $-66^{\prime} 3$ & $-0^{\prime} 4$ & $-46^{\prime} 9$ \\
\hline BNG & & & & & $-0^{\prime} 5$ & -8 & $-0^{\prime} 31$ & $-35^{\prime} 3$ & $-0^{\prime} 46$ & $-35^{\prime} 2$ & $-0^{\prime} 23$ & $-28^{\prime} 8$ \\
\hline PSP & $-2^{\prime} 7$ & $-283^{\prime} 0$ & & & & & & & & & & \\
\hline CDS & & & $-2^{\prime} 3$ & $-98^{\prime} 6$ & $-1^{\prime} 7$ & -8 & & & & & & \\
\hline UPyD & & & & & & & & & & & $-1^{\prime} 5$ & $-79^{\prime} 0$ \\
\hline
\end{tabular}

CUADRO N. ${ }^{0} 5$. TAMAÑo de LAS CIRCUNSCRIPCIONES Y \% DE DIPUTADOS ELEGIDOS EN ELLAS (2008)

\begin{tabular}{|l|c|c|c|c|c|c|}
\hline \multirow{2}{*}{} & \multicolumn{2}{|c|}{ Pequeñas } & \multicolumn{2}{c|}{ Medianas } & \multicolumn{2}{c|}{ Grande } \\
\cline { 2 - 7 } & $N .^{\circ}$ & $\%$ & $N^{\circ}$ & $\%$ & $N^{\circ}$ & $\%$ \\
\hline Circunscripciones*, ** $^{*}$ & 25 & 50 & 20 & 40 & 5 & 10 \\
\hline Diputados** $^{*}$ & 97 & 28 & 145 & $41^{\prime} 5$ & 106 & 30,5 \\
\hline
\end{tabular}

* No se incluyen Ceuta ni Melilla, con sendos diputados, elegidos lógicamente por el sistema de mayoría.

** Redondeando los decimales en el medio punto o punto entero más próximo.

(C) UNED. Revista de Derecho Politico 
Title

THE REFORM OF THE ELECTORAL SYSTEM OR THE QUADRATURE OF THE CIRCLE.

\section{Summary}

1. INTRODUCTION. 2. GENERAL CONCEPTS. 3. AN INITIAL QUESTION AND WORK HYPOTHESIS. 4. - ORIGIN OF THE SPANISH ELECTORAL SYSTEM AND FIRST FORMATION OF THE SYSTEM OF PARTIES. 5. - LATER EVOLUTION. 6. INTERMISSION: ELECTORAL AND PARTIES SYSTEM OF THE AUTONOMOUS COMMUNITIES. 7. HOMOGENIZATION OF THE BEHAVIOR OF THE ELECTORATE IN THE GENERAL AND AUTONOMOUS ELECTIONS. 8. THE ABANDONMENT OF THE INITIAL OPTION OF THE SYSTEM: THE BAD TWO-PARTY SYSTEM AND THE GOOD MULTI-PARTY SYSTEM. 9. THE NATIONALIST PARTIES. 10. MAJORITY OF VOTES, MAJORITY OF SEATES AND FORMATION OF GOVERNMENT, THREE ELECTORAL EFFECTS NOT ALWAYS SEQUENTIAL. 11. CONCLUSIONS OF THE PREVIOUS ANALYSIS. 12. THE REFORM PROPOSALS. 13. THE REPRESENTATION AS REFLECTION AND INTEGRATION IN THE SYSTEM. 14. FINAL PROPOSAL. 15. A EPILOGUE FROM THE PERPLEXITY.

\section{Resumen}

El autor analiza en este trabajo diferentes propuestas de reforma del sistema electoral español. Para ello, parte del estudio del origen y la evolución del sistema, así como su relación con el sistema de partidos. Aunque el estudio se centra en las elecciones al Congreso de los Diputados, también se analizan otras como las autonómicas. Después de analizar la evolución del comportamiento electoral en España, tanto en elecciones generales como autonómicas, y su relación con el sistema de partidos, se concluye que la tendencia es a la de un cuasi-bipartidismo, con algunas excepciones en las elecciones autonómicas de Comunidades con fuerte implantación de partidos nacionalistas. El autor analiza algunas de las propuestas de reforma actuales, que podrían acercarse más a un multipartidismo. Finalmente, en el trabajo se sugiere como alternativa el sistema electoral alemán, y se denuncia la actual radicalización del bipartidismo, con la falta de acuerdo entre los dos grandes partidos españoles. 


\begin{abstract}
The author analyzes in this work different propose from reform of the Spanish electoral system. For it, he part of the study of the origin and the evolution of the system, as well as its relation with the system of parties. Although the study is centered in the elections the Congress of the Deputies, also analyze others like the autonomic ones. After analyzing the evolution of the electoral behavior in Spain, as much in general elections as autonomic, and their relation with the system of parties, he concludes that the tendency is to the one of a cuasi-two-party system, with some exceptions in the autonomic elections of Communities with strong implantation of nationalistic parties. The author analyzes some of the present proposals of reform, that could approach a multi-party system. Finally, in the work the German electoral system is suggested like alternative, and the present radicalization of the bipartisanism is denounced, with the lack in agreement between the two great Spanish parties.
\end{abstract}

Palabras clave

Sistema electoral español, reforma del sistema electoral

\title{
Key words
}

Spanish electoral system, Reform of the electoral system

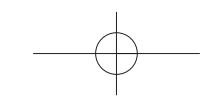

